Abstract
The slower spread of AIDS in South Asian countries, combined with the fact that
most South Asian countries have higher per capita incomes than the most severely
affected countries of other regions imply that the various impacts of the disease will
be smaller in South Asia than in the worst affected countries in other regions. While
justified with respect to the impact of the disease on economic output, on poverty, or
on orphanhood, this conclusion does not follow with respect to the health sector,
where the relatively minor public role in health care delivery and the entrepreneurial
and heterogeneous private health and pharmaceutical sectors combine to magnify
the potential impact of the epidemic.
This paper uses recent epidemiological data on the extent and rate of spread of
HIVIAIDS in South Asian countries and alternative scenarios regarding future
government efforts to expand access to AIDS treatment in order to estimate the
future need for antiretroviral treatment in South Asian countries and the fiscal
burden that their governments will shoulder if they decide to provide or finance all of
the needed care. Since AIDS treatment cannot be presumed to slow HIV
transmission and may speed it, the usual argument for paying for such treatment
with public funds is on equity grounds- that it will prevent poverty and orphanhood.
Indeed this paper estimates that public financing of AIDS treatment might avert
poverty for about three percent of the Indian population, for example. However,
data on the quality of private health care in India suggests that another effect of
publicly produced AIDS treatment would be to crowd out lower-quality private AIDS
treatment, thereby preventing some of the negative spillovers of poor quality private
treatment. The paper closes by arguing on efficiency grounds that the government
role in AIDS treatment should encompass both regulation of the private sector and
support for quality "structured" AIDS treatment in the public sector.

The Center for Global Development is an independent, nonprofit policy research organization that is dedicated to reducing global poverty and inequality and to making globalization work for the poor. This paper was made possible by financial support from the Bill \& Melinda Gates Foundation.

Use and dissemination of this Working Paper is encouraged; however, reproduced copies may not be used for commercial purposes. Further usage is permitted under the terms of the Creative Commons License. The views expressed in this paper are those of the author and should not be attributed to the board of directors or funders of the Center for Global Development. 
Mead Over. 2009. "AIDS Treatment in South Asia: Equity and Efficiency Arguments for Shouldering the Fiscal Burden When Prevalence Rates Are Low." Working Paper 161. Washington, D.C.: Center for Global Development. http://www.cgdev.org/content/publications/detail/1421119/ 


\title{
Al DS Treatment in South Asia: Equity and Efficiency Arguments for Shouldering the Fiscal Burden When Prevalence Rates Are Low
}

\author{
Mead Over \\ Senior Fellow \\ Center for Global Development
}

\begin{abstract}
The slower spread of AIDS in South Asian countries, combined with the fact that most South Asian countries have higher per capita incomes than the most severely affected countries of other regions imply that the various impacts of the disease will be smaller in South Asia than in the worst affected countries in other regions. While justified with respect to the impact of the disease on economic output, on poverty, or on orphanhood, this conclusion does not follow with respect to the health sector, where the relatively minor public role in health care delivery and the entrepreneurial and heterogeneous private health and pharmaceutical sectors combine to magnify the potential impact of the epidemic.

This paper uses recent epidemiological data on the extent and rate of spread of HIV/AIDS in South Asian countries and alternative scenarios regarding future government efforts to expand access to AIDS treatment in order to estimate the future need for antiretroviral treatment in South Asian countries and the fiscal burden that their governments will shoulder if they decide to provide or finance all of the needed care. Since AIDS treatment cannot be presumed to slow HIV transmission and may speed it, the usual argument for paying for such treatment with public funds is on equity grounds-that it will prevent poverty and orphanhood. Indeed this paper estimates that public financing of AIDS treatment might avert poverty for about three percent of the Indian population, for example. However, data on the quality of private health care in India suggests that another effect of publicly produced AIDS treatment would be to crowd out lower-quality private AIDS treatment, thereby preventing some of the negative spillovers of poor quality private treatment. The paper closes by arguing on efficiency grounds that the government role in AIDS treatment should encompass both regulation of the private sector and support for quality "structured" AIDS treatment in the public sector.
\end{abstract}




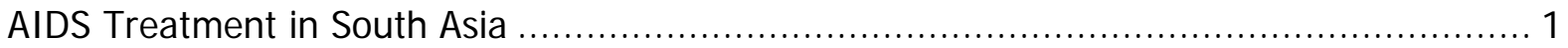

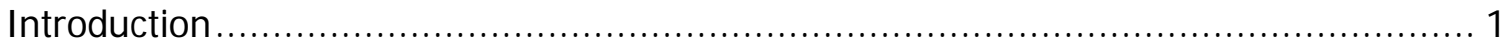

Overview of AIDS cases and treatment in South Asia ........................................ 2

Future growth of South Asian treatment costs.......................................... 7

Health care financing in South Asian countries .......................................... 10

Access to Private Health Care and the Risk of Poverty .......................................

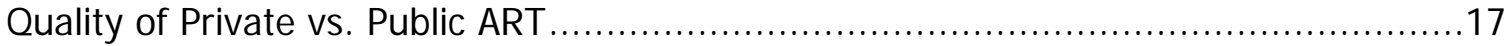

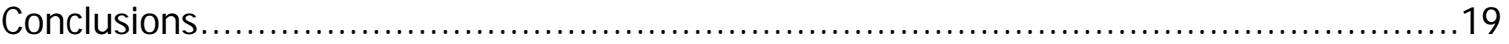

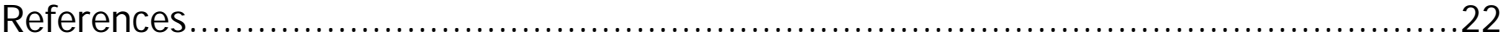

Tables

Table 1. Estimated Numbers of People Requiring and Receiving ART, end-2007 ............ 4

Table 2. Shares of Private and Public Health Care Production in India, ....................... 12

Table 3. Poverty head counts: effect of accounting for out-of-pocket payments for

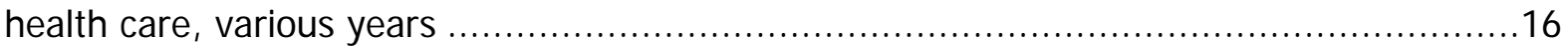

Figures

1. South Asia and India: Contribution of HIV/AIDS to Mortality ............................... 3

2. HIV Treatment in Centers Supported by the National AIDS Control Organization............ 5

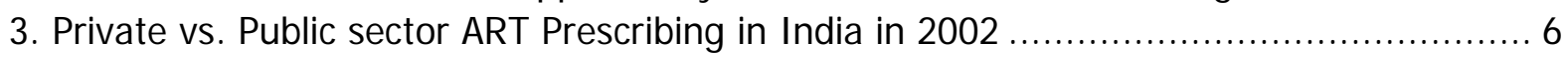

4. Projected AIDS treatment burden in India assuming rapid scale up......................... 9

5. Projected AIDS treatment burden in Nepal assuming rapid scale up ......................... 9

6. Total health expenditures per capita in South Asia and sub-Saharan Africa..................11

7. Financing of health expenditures in South Asia and sub-Saharan Africa ........................ 12

8. Impact of health expenditure on household net consumption patterns in India............14

Appendices

1. Projected fiscal burden of AIDS treatment in Four South Asian Countries ....................24

2. Projected fiscal burden of AIDS treatment for South Asia \& sub-Saharan Africa .............27

3. A model for projecting future AIDS treatment costs ...................................... 28

4. Projected annual cost of treating AIDS patients in 6 South Asian Countries ..................30 


\section{AI DS Treatment in South Asia: Equity and Efficiency Arguments for Shouldering the Fiscal Burden When Prevalence Rates Are Low ${ }^{1}$}

\section{Introduction}

In South Asia HIV and AIDS are less prevalent than in sub-Saharan Africa or in severely affected countries of the Caribbean, South East Asia or the Pacific I slands. The slower spread of AIDS, combined with the fact that most South Asian countries have higher per capita incomes than the most severely affected countries of other regions suggest that the various impacts of the disease will be smaller in South Asia than in other regions. While this conclusion is generally justified with respect to the impact of the disease on economic output, on poverty or on orphanhood, it does not necessarily follow with respect to the health sector, where particular features of supply and demand can magnify the impact of any given rate of HIV infection.

Our analysis is broadly divided into two main parts. The first part of the chapter takes stock of the scale of the challenge to health sectors in South Asia. This part sets out with an overview of the numbers of AIDS cases and the availability of treatment in South Asia (Section 2), including a review of the available evidence regarding the provision of antiretroviral therapy through public and private health services. The following Section 3 looks forward, providing new estimates of the costs of AIDS treatment through the year 2020 for 6 South Asian countries, ${ }^{2}$ on the assumption that countries will attempt to provide universal access to AIDS treatment.

The second part of the chapter considers the implications of specific features of the supply and demand for health care in South Asia for the impact of the projected increased demand for AIDS treatment on South Asian health sectors, focusing on the roles of the private vs. the public health care providers. This emphasis reflects the fact that the public health systems of the South Asian region provide a much smaller proportion their citizens'

\footnotetext{
${ }^{1}$ This paper was made possible by financial support from the Bill \& Melinda Gates Foundation. The author is grateful to Agnes Couffinal, Paolo Belli, Charlie Griffin and Phil Musgrove for detailed comments and to Martina Tonizzo for expert research assistance. The author also thanks Mariam Claeson and Markus Haacker, without whose patient unceasing support this paper would not exist. Thanks also to J ohn Stover who generously commented on early versions of the projection model presented in Annex 3 and used for the projections of treatment and fiscal loads in section IV of the paper and to Martina Tonizzo for research assistance. The model constructed by Stover and Bollinger using Spectrum has similar objectives to the one developed here. (http://www. futuresinstitute.org/ and

http://www.unaids.org/en/MediaCentre/PressMaterials/FeatureStory/20070925_Resource needs_met hodology.asp). An earlier version of this paper appears as a chapter in Claeson and Haacker (2009).

${ }^{2}$ Owing to data constraints, the analysis presented in this chapter focuses on Bangladesh, Bhutan, India, Nepal, Pakistan and Sri Lanka, and excludes Afghanistan and the Maldives.
} 
health care than do the systems of countries outside the region which are severely affected by AIDS (Section 4). With the notable exception of Sri Lanka, three-quarters or more of health expenditures in the region are financed privately, and little or none of the private payments are mediated by third-party payers like insurance agencies. The fact that much of South Asia is poorly provided with public facilities or public sector health finances suggests that many of these people who would in other countries frequent the public facilities, will instead seek care from a nearby private practitioner, either modern or traditional.

In a context where public health services and third-party payers like insurance agencies play a relatively minor role, the high costs of antiretroviral therapy (ART) have implications for access to such treatment and expose households to the risk of poverty. Section 5 discusses the impact of health expenditures on poverty in general, and arrives at conjectures regarding the impacts of HIV/AIDS-related health expenditures on poverty.

Since AIDS treatment cannot be presumed to slow HIV transmission and may speed it, the usual argument for paying for such treatment with public funds is on equity grounds that it will prevent poverty and orphanhood. However, Section 6 of this chapter argues that publicly produced AIDS treatment might crowd out lower quality private AIDS treatment, thereby preventing some negative spillovers of poor quality treatment. The section reviews the evidence that suggests that this effect of public treatment might be sufficient to justify government support on efficiency grounds.

Finally, a concluding section summarizes the findings of the chapter, and suggests their policy implications for South Asian governments.

\section{Overview of AI DS cases and treatment in South Asia}

Knowledge of the burden of AIDS in South Asia became dramatically more precise with the release in 2006 of the country's first population-based survey which collected and analyzed blood samples in order to accurately measure the proportion of India's population that is infected with HIV. Since India is the region's largest country, the adjustment of its estimated prevalence rate from almost one percent early in 2006 down to approximately 0.3 percent after release of the survey has erased more than three million putative cases of HIV infection from the region.

The implications of this correction for the epidemiology and the economic impact of AIDS in India are addressed elsewhere (Claeson and Haacker, 2009, various chapters). Here it is sufficient to note that a smaller prevalence rate means that the epidemic has caused a smaller increase in the demand for health care than might previously have been conjectured. Figure 1 shows the distribution of the current burden of disease, showing that HIV/AIDS accounts for 1 1/2 percent of all deaths in South Asia and about 2 percent of all deaths in India. Haacker (ibid, chapter 3) points out that these numbers of deaths are comparable to the numbers from diabetes, tuberculosis and measles. 
What will these pie charts look like in the future? Recent evidence suggests that, in accordance with the pattern typically observed during an epidemiologic transition, measles is declining as a cause of death in the region, while diabetes and tuberculosis are both increasing. While diabetes is a life-style disease associated with the increasing prevalence of obesity, tuberculosis is an opportunistic illness which takes advantage of weakened immune systems, and thus can be spread by AIDS. Thus, if HIV continues to spread at the rate it has spread in the past, it is likely to become substantially more important than measles and may outpace diabetes. Whether HIV or TB will grow faster will depend on the vigor of programs to prevent and treat them.

Figure 1. South Asia and India: Contribution of HIV/AIDS to Mortality
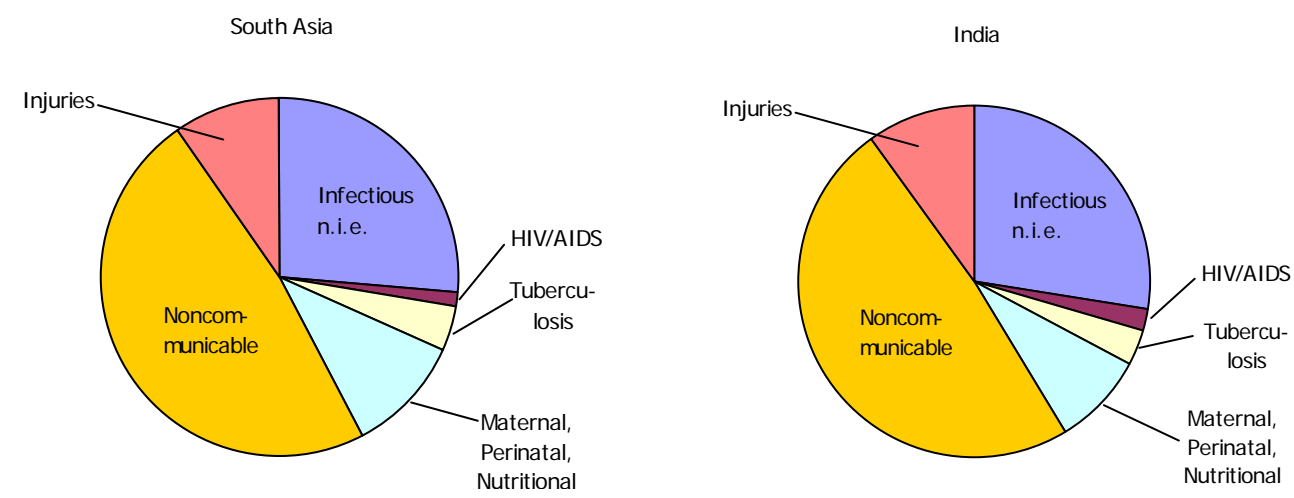

Source: Haacker (present volume).

Table 1 presents estimates by WHO, UNAIDS and UNICEF (2008) of the number of people receiving AIDS treatment and the number needing it in each South Asian country. While the number of people receiving treatment is based on real, even if somewhat incomplete, data from regional health ministries, the number of people estimated to need treatment is extrapolated from epidemiologic projection models and is thus dependent on the available HIV prevalence data. 
Table 1. Estimated Numbers of People Requiring and Receiving ART, end-2007

\begin{tabular}{lrrrrrr}
\hline & \multicolumn{3}{c}{ People receiving ART } & \multicolumn{3}{c}{ People needing ART } \\
\hline & \multicolumn{1}{c}{$\begin{array}{c}\text { Point } \\
\text { estimate }\end{array}$} & \multicolumn{1}{c}{$\begin{array}{c}\text { Lower } \\
\text { range }\end{array}$} & $\begin{array}{l}\text { Upper } \\
\text { range }\end{array}$ & $\begin{array}{c}\text { Point } \\
\text { estimate }\end{array}$ & $\begin{array}{l}\text { Lower } \\
\text { range }\end{array}$ & \multicolumn{1}{c}{$\begin{array}{l}\text { Upper } \\
\text { range }\end{array}$} \\
\hline Bangladesh & $<200$ & & $<200$ & 2400 & 1500 & 4000 \\
Bhutan & $<100$ & & $<100$ & $<100$ & $<100$ & $<100$ \\
India & 158000 & 138000 & 178000 & $\ldots$ & 630000 & 1600000 \\
Nepal & 1400 & 1300 & 1600 & 20000 & 13000 & 30000 \\
Pakistan & 600 & 500 & 600 & 20000 & 13000 & 34000 \\
Sri Lanka & $<200$ & $<100$ & $<200$ & 780 & 540 & 1100 \\
\hline Source: All
\end{tabular}

Source: All figures except those for India's need are from World Health Organization, UNAIDS, UNICEF, "Towards Universal Access: Scaling up priority HIV/AIDS interventions in the health sector," Progress Report, June 2008. Need for ART in India is missing in the 2008 report so this table uses figures from the 2007 issue of the same report. (ART = antiretroviral therapy for AIDS)

In India, the recently announced adjustments in the estimated number of HIV infected give credence to the lower estimate of 630,000 needing treatment and suggest that the upper estimate of 1.6 million is obsolete. Since the ratio of those receiving treatment to those needing it is defined as the coverage rate, the choice of 630,000 as the denominator means that India has achieved a fifteen percent coverage rate rather than only a six percent coverage, welcome news to those striving for maximal coverage.

Figure 2 presents data on the scale up of central government financed antiretroviral therapy (ART) to a total of about 56,500 patients in January, 2007. The most remarkable feature of the scale-up depicted in Figure 2 is its constantly increasing upward slope. Like Thailand, Botswana and a few other countries, India has been able to accelerate its treatment program during the launch phase. While one can ask whether the patient numbers represent surviving patients or replacements recruited when a patient dies or is lost-to-follow-up, the achievement of continued acceleration over a three year period is remarkable and sets a high standard for coming years. 
Figure 2. HIV Treatment in Centers Supported by the Indian National AIDS Control Organization, India, April 2004 through J anuary 2007.

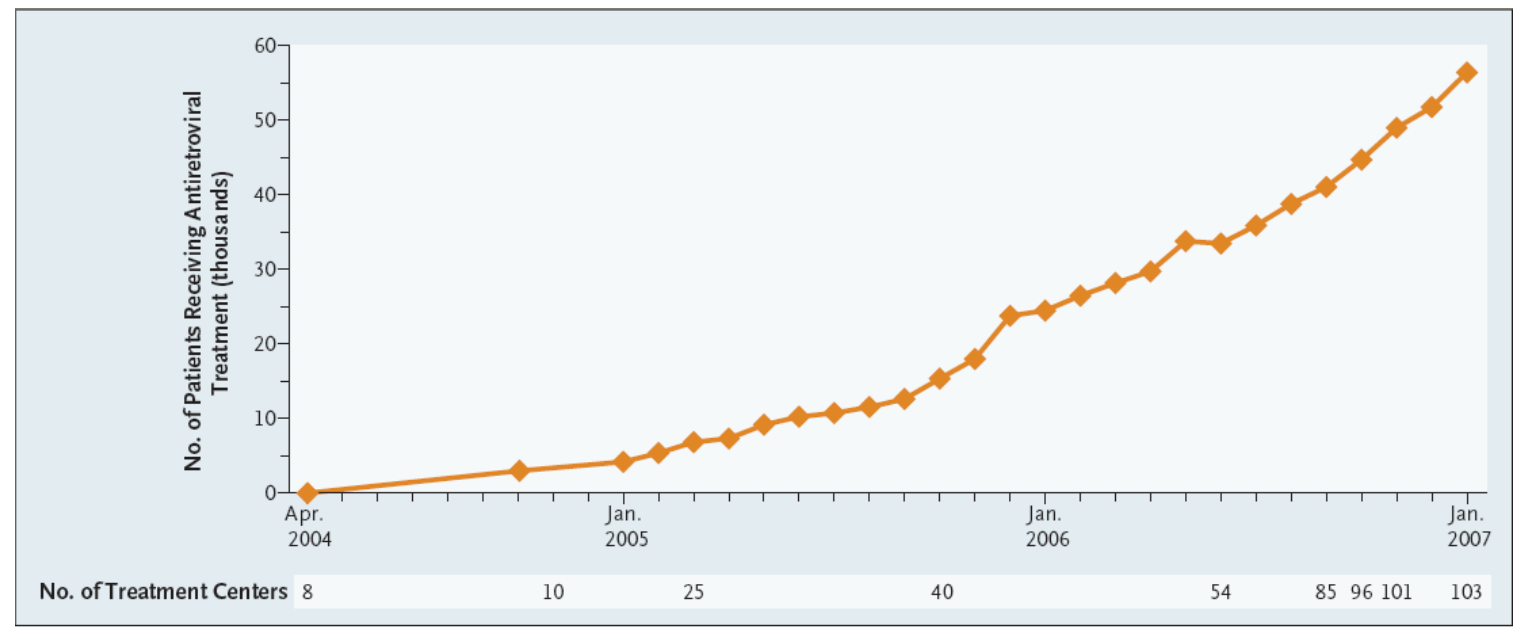

Source: NACO as cited by Steinbrook, 2007. WHO (2008) cites newer NACO figures which count 118,052 people receiving ART in December, 2007 at 137 sites.

Estimates for the number of patients receiving ART in India from non-governmental sources are extremely conjectural. Steinbrook (2007) estimates between 10,000 and 20,000. WHO's April 2007 progress report gives an estimate of 25,000 receiving ART in the unorganized or "unstructured" private health sector (see WHO, UNAIDS, and UNICEF (2007)). This brings the estimated total under treatment in 2006 to about 95,000. By December, 2007, the updated WHO report estimates a total of 158,000 under treatment, including about 5,000 treated by NGOs and 35,000 in the for-profit private sector. Thus for two years running the Indian government has estimated that it is treating three out of four Indian ART patients, with one out of four being treated in the formal and informal private sector. Since the private sector provides over 80 percent of all health care in India, these estimates suggest that Indians depend much more on the public sector for AIDS treatment than they do for other health care services.

It is also possible, however, that NACO and WHO have greatly underestimated the amount of private sector provision. For example, using data from two surveys of Indian physicians, one by mail and another conducted by the representatives of a major pharmaceutical firm, a study performed in 2002 found substantial ART prescribing among non-government physicians (Hira, 2002). The representativeness of neither of these two samples can be assured. The former suffered from a response rate of only 30 percent, while the latter was a convenience sample selected by the pharmaceutical company, which is likely to be biased towards high-volume prescribers. Within the sample collected by the pharmaceutical companies, about a third of the respondents were employed by government hospitals, while $46 \%$ were in private clinics and $22 \%$ in Trust Hospitals. Given that many of the government employees in the sample also practice part time from private clinics, this distribution plausibly captures some features of the population of Indian physicians. 
Respondents were asked whether they prescribed antiretroviral medications. Their selfreported answers were coded as "Never", "Occasionally" or "Frequently". Figure 3 presents the results. Note that the more independent of the government was the affiliation of the physician, the more likely he was to prescribe ART, with the highest frequency being in practitioners in private clinics. This was in 2002, before India began to expand availability of ART with the establishment of AIDS Treatment Centers. The pattern partly reflects the fact that the pharmaceutical company was approaching and surveying its usual clients, who are probably high-volume prescribers. However, even taking this possible source of bias into account, the pattern shows that many private sector physicians were fully engaged in ART treatment.

Figure 3. Percent of physicians who report prescribing ART "frequently" by type of institutional affiliation in India in 2002

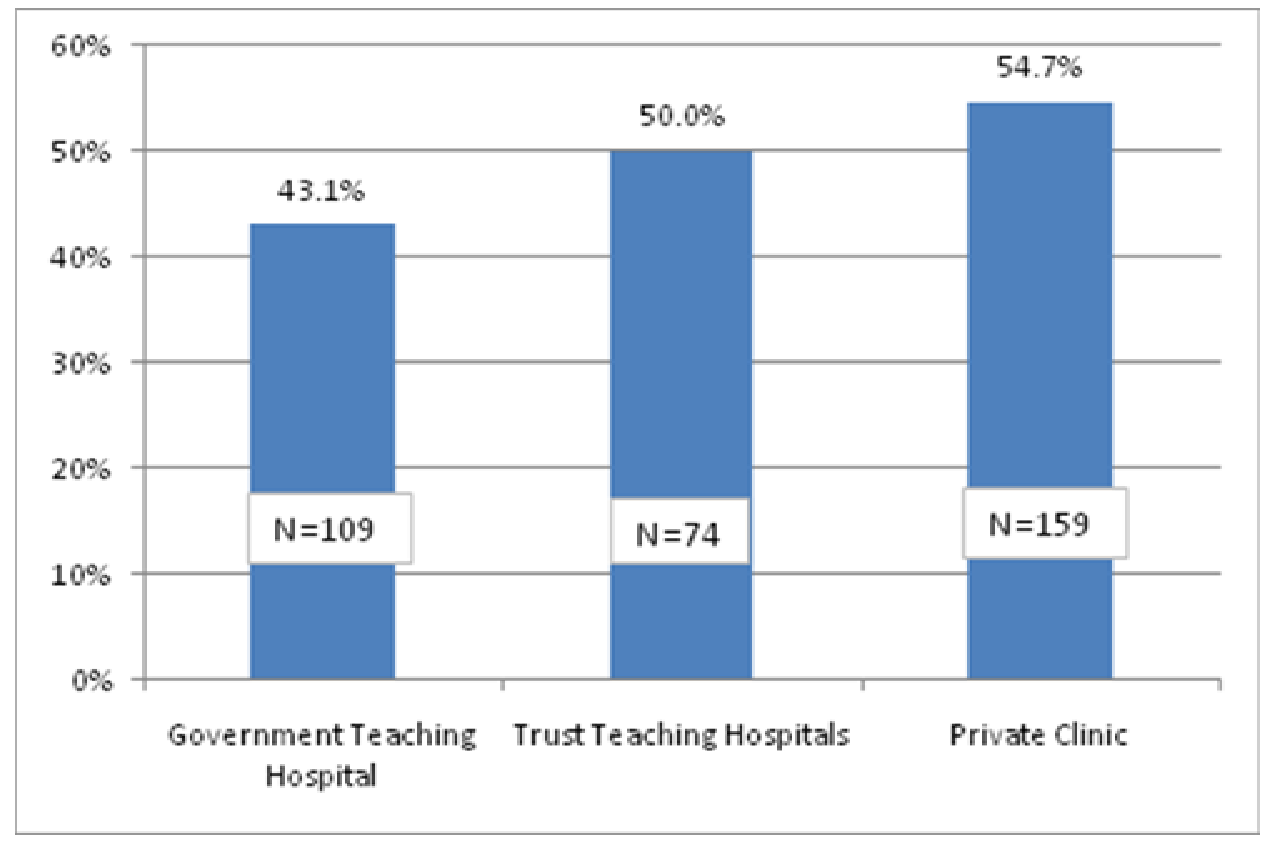

Assuming these surveys to be representative, a perhaps heroic assumption, the authors of the study estimated that about 90,000 Indians were receiving ART in 2002 at a time when the government was formally delivering treatment to only a few thousand patients. Thus an upper bound to the number of patients receiving ART in the private sector in 2005 is on the order of $100,000-200,000$. Assuming that most of the patients previously treated in the private sector in 2005 remain under treatment in the private sector, then the 118,000 patients receiving government financed ART in December 2007 are only one-third to onehalf of all the Indians currently under treatment. Thus, it is safe to say that somewhere between 25 and 67 percent of AIDS care in India is currently being delivered by the private sector. 


\section{Future growth of South Asian treatment costs}

For patients who benefit from antiretroviral therapy, AIDS is a chronic disease. Given current technology, patients will need to take their AIDS medication every day for the rest of their lives. Thus, the fiscal and organizational burden of treating AIDS patients accumulates over time as patients who begin treatment each year are added to the stock of patients still alive from previous years.

Figures 4 and 5 present the projected burden of treatment costs for two of the South Asian countries, India and Nepal. Both figures are generated by the same model which is described in Annex 3. Given assumptions regarding the success of antiretroviral therapy and the rate of new cases of HIV infection, the calculations presented in these figures are based on the assumption that all South Asian countries adopt much more rapid scale up of antiretroviral therapy consistent with the ambition to achieve "universal coverage" as quickly as possible (Shrestha, Bhatta, and Bhatta, 2006). The four panels in the two figures present the projected number of patients (in the northwest panel), the costs of the program in each year (in the northeast corner), the percentage of the cost for those remaining from previous years, here called the "entitlement", (in the southwest corner) and the treatment cost as a percent of health and total public expenditure (southeast). ${ }^{3}$

The first thing to note in comparing the figures for India and Nepal is the difference in scale, measured on the vertical axis in each of the four panels. While India's number of patients on treatment rises from less than 100,000 to 2.5 million in the year 2020, Nepal's number is 30 times smaller, rising to about 100,000 at the end of the period. Similarly the ratio between projected annual AIDS expenditures in the year 2020 also differ by a factor of 30 , with India projected to spend about 2 billion dollars that year and Nepal "only" 60 million dollars.

Among other assumptions detailed in Annex 3, the model assumes that 4 percent of those who survive one year on AIDS treatment will experience "treatment failure" each year and then be given much more expensive "second line" therapy. We assume that on top of a constant $\$ 278$ per year in clinic time, first-line drugs cost $\$ 227$ a year, while second-line therapy costs $\$ 2,681$. As a result of these assumptions, the projections for both India and Nepal (and for the other countries shown in Annexes 1 and 2) the portion of total costs consumed by second-line therapies is much larger than the portion of patients who receive them. (Compare the line for second-line patients in the northwest quadrant with the line for second-line patients in the northeast quadrant.) By 2020 more than 20 percent of

\footnotetext{
${ }^{3}$ Figures 4 and 5 share the assumption that the "incidence rate" of new cases declines at a modest 5 percent each year from its historical level. This assumption is also embodied in the two right-hand tables in Annex 4.
} 
treatment costs will be for second-line therapy, a fact that raises the urgency of efforts to bring down the cost of these more sophisticated and newer AIDS drugs. ${ }^{4}$

Government will also want to know what share of their various budgets will be consumed by the accumulating costs of AIDS treatment. One way to address this issue is to project forward each country's total health expenditure under the assumption that it remains the same percentage of GDP as in 2004 (the last year for which we have data). The southeast panel of the two figures shows the projections that AIDS treatment in India will rise to absorb about 6 percent of the central health budget, while in Nepal it would rise to consume about a fifth of the health care budget. Of course in both countries, the health budget might be expanded in order to absorb AIDS treatment expenditure, meaning that the major cost of AIDS treatment would be foregone funding in sectors from which the funds are reallocated.

These projections for India and Nepal both assume rapid scale-up of ART, indeed more rapid than was promised by the Indian National AIDS Control Organization in its various announcements. At the other extreme, suppose that countries are only able to maintain the rate of scale up that they have already demonstrated since 2003/4. As we saw for India in Figure 2, this "historical" rate of expansion has been steady and accelerating, but moderate. The result will be much lower costs in the year 2020. Comparing the top and bottom rows of Annex 4, we can see that rapid scale-up will cost about 6 times as much per year by the year 2020, compared to historical scale-up. Of course, under slower scale up the countries will lose millions of people to AIDS deaths who might otherwise have had extended lives.

\footnotetext{
${ }^{4}$ The greatest uncertainty in these projections is with regards to the annual cost of second-line therapy. While the costs of clinic time and of first-line therapy are unlikely to change much, second line therapy could either decline or increase in average cost. Second line prices might decline due to negotiated price reductions and/or exercise of TRIPS provisions which allow a country to issue a "compulsory license" for domestic manufacture of a pharmaceutical product under certain conditions. But there will be upward pressure on second line costs from the advent of newer medications, the increasing complexity of care for patients who fail first-line treatment, the usual increase in costs with increasing scale and the globalization of the Indian pharmaceutical industry. Since the outcome of these conflicting trends is not clear, the projections presented here assume that unit costs remain constant for both first- and second-line medications.
} 
Figure 4. Projected AIDS treatment burden in India assuming rapid scale up

AIDS Treatment: Numbers, costs \& entitlement Total for country IND
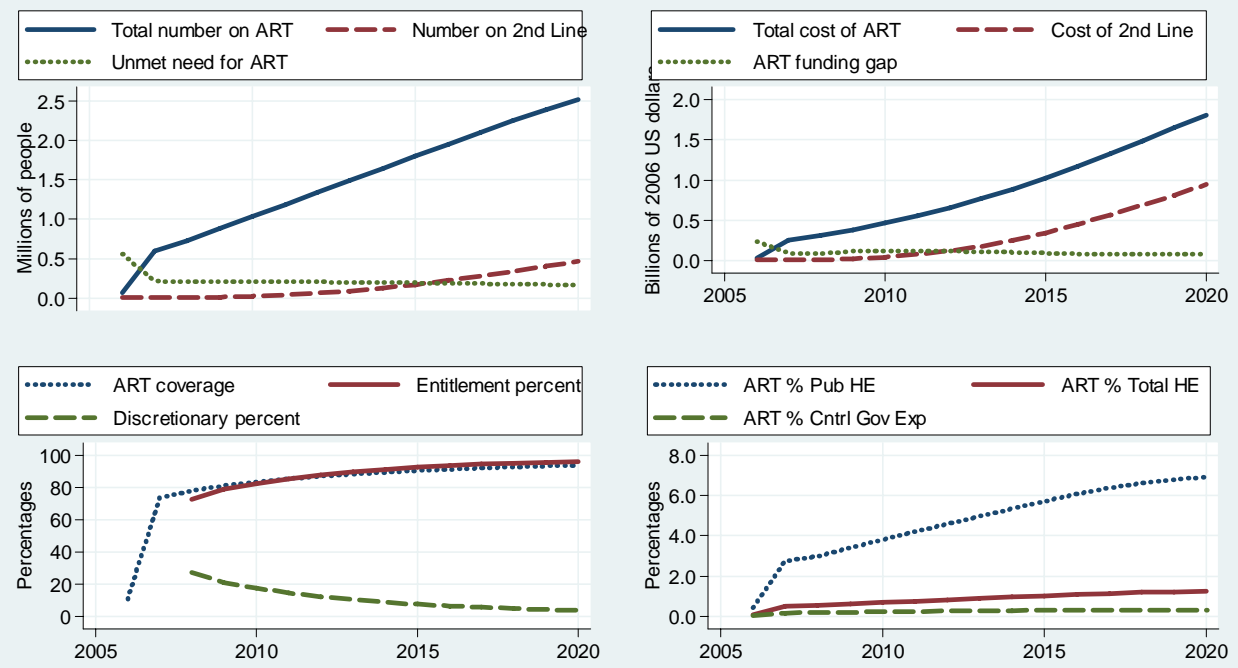

Adjusting at $95.0 \%$ of unmet need each year

adrate $1=.13$, adrate $2=.04$, bdrate $=.01$, Erate $=.11$, ndrate $=.3$, incdwn $=.95$

Source: Author's projections.

Figure 5. Projected AIDS treatment burden in Nepal assuming rapid scale up

AIDS Treatment: Numbers, costs \& entitlement Total for country NPL
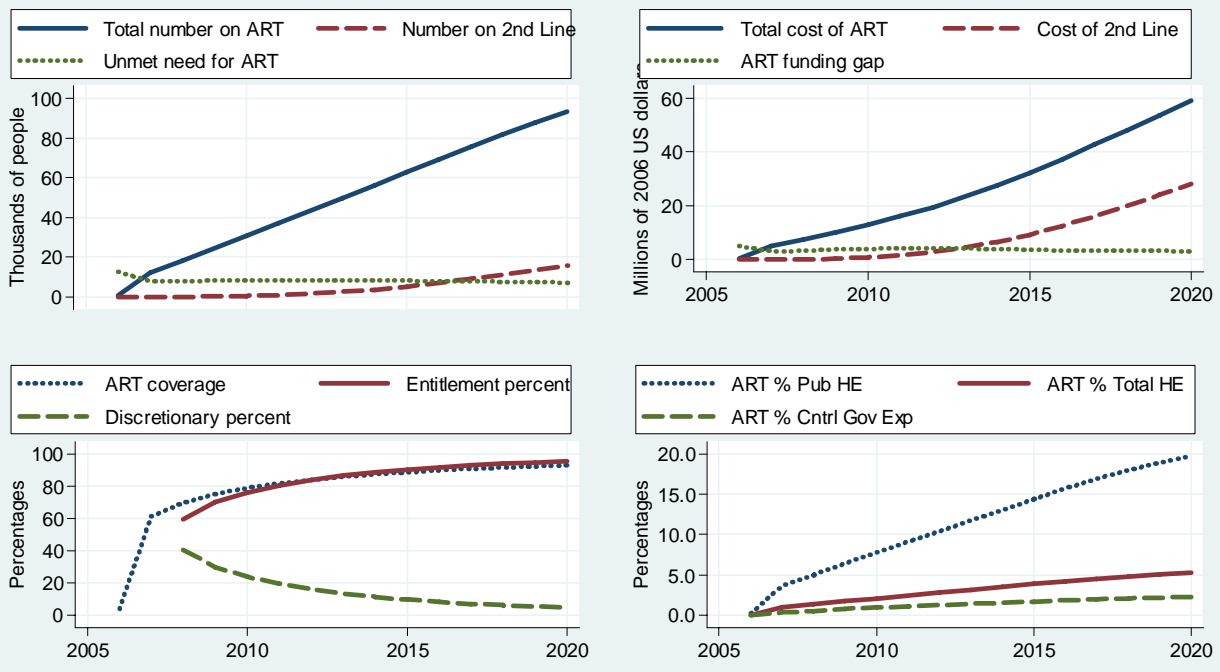

Adjusting at $95.0 \%$ of unmet need each year

adrate $1=.13$, adrate $2=.04$, bdrate $=.01$, Erate $=.11$, ndrate $=.3$, incdwn $=.95$

Source: Author's projections. 
Annex 1 presents similar projections for the South Asian countries of Bangladesh, Bhutan, Sri Lanka and Pakistan. Annex 2 presents a single graph for the aggregates across all the countries of South Asia (comparable to the tables in Annex 4) and a second single graph for all of sub-Saharan Africa. Sub-Saharan Africa as a unit is projected to be treating 30 million people by the year 2020 at an annual cost of 25 billion dollars. In the absence of assistance, AIDS treatment will be amount to about 80 per cent of what would have been the health budget of the average African country. Since Africa benefits from greater inflows of grant support for AIDS treatment than does South Asia, African governments may not be asked to cover a large share of these extraordinary costs. ${ }^{5}$

\section{Health care financing in South Asian countries}

Although per capita incomes are higher in South Asia than in many African countries, the two continents are on a par with respect to total health expenditure per capita. Figure 6 presents a box and whisker plot showing on the left side the distribution of total health expenditure per capita in the six South Asian countries and on the right the distribution of the same variable for sub-Saharan Africa. Although there are several outliers above the African graph, capturing the wealthiest countries on that continent, the center of the distribution is similar in both cases, with the median for both distributions being under $\$ 20$ per person.

\footnotetext{
${ }^{5}$ The magnitude of AIDS treatment funding relative to health system capacity may crowd out funding of other health system activities in recipient countries (Over, 2004). And the magnitude of such funding relative to total foreign assistance by any given donor may crowd out other types of foreign assistance at the source, particularly for the largest bilateral donor (Over, 2008).
} 
Figure 6. Total health expenditure per capita is similar in South Asia and sub-Saharan Africa, except for 6 outlier African countries.

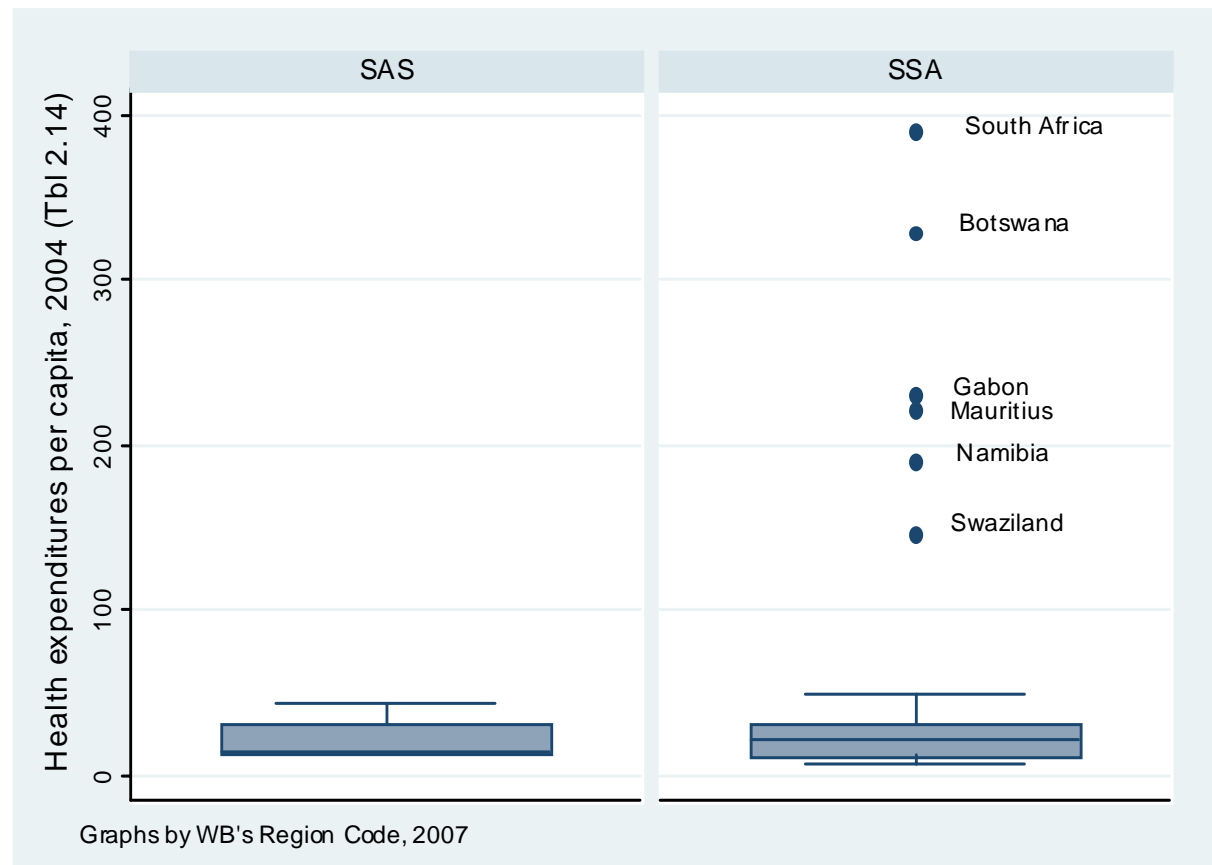

Source: Author's construction from World Bank (2007).

The importance of the private health care sector in a country can be analyzed from either the production or the expenditure perspective. Table 2 presents data on the production side of the Indian health sector from the period 1986 through 1995. The public share of both public and private health care production clearly declined in that decade with the private share reaching 80 percent of outpatient care and almost 60 percent of inpatient care (Sengupta and Nundy (2005)). Data from the 2004 National Sample Survey shows no change in private sector dominance of out-patient care and increased private sector dominance of inpatient care. ${ }^{6}$ In view of the growth of the private sector Indian economy since 1995 and the greatly increased inequality of the income distribution, it would not be surprising to find that the private component accounted for an even larger share of the health care sector in 2008 than it did in 2004. Since successful AIDS treatment is delivered on an out-patient basis, these data support the view that many Indian patients are likely to seek and receive ART from the private sector.

\footnotetext{
${ }^{6}$ Thanks to an anonymous reviewer for supplying the 2004 figures for this table. The data is advertised on the web site of the statistical office at http://mospi.nic.in/mospi_nsso_data.htm.
} 
Table 2. Shares of Private and Public Health Care Production in India,

\begin{tabular}{lcccccc}
\hline & \multicolumn{2}{c}{$1986-87$} & \multicolumn{2}{c}{$1995-96$} & \multicolumn{2}{c}{2004} \\
\hline & Rural & Urban & Rural & Urban & Rural & Urban \\
\hline Not treated & 18 & 11 & 17 & 9 & 18 & 11 \\
$\quad$ Treated as outpatients & 26 & 28 & 19 & 20 & 22 & 19 \\
$\quad$ Public & 74 & 72 & 81 & 80 & 78 & 81 \\
$\quad$ Private & & & & & & \\
Treated as inpatients & 60 & 60 & 44 & 43 & 42 & 38 \\
$\quad$ Public & 40 & 40 & 56 & 57 & 58 & 62 \\
$\quad$ Private & & & & & & \\
\hline Sote:
\end{tabular}

Source: Indian National Sample Survey Organization $(1992,1998)$ as cited in Peters, Yazbeck and others,

Better Health systems for India's Poor, 2002, Chapter 2, Table 2.4, p.48.

The two panels of Figure 7, analyze the public/private roles from the expenditure perspective, comparing the South Asia region to sub-Saharan Africa. Panel a) of Figure 6 shows that unlike total health expenditure, public health expenditure is distributed very differently in the two regions, with African governments being typically more generous than South Asian ones. While the median country in South Asia covers only about one fifth of health care costs out of public money (with India covering even less and Sri Lanka much more), the median country in Africa covers about half of health expenditure.

Figure 7. South Asian countries offer less public financing and less insurance financing than do most African governments
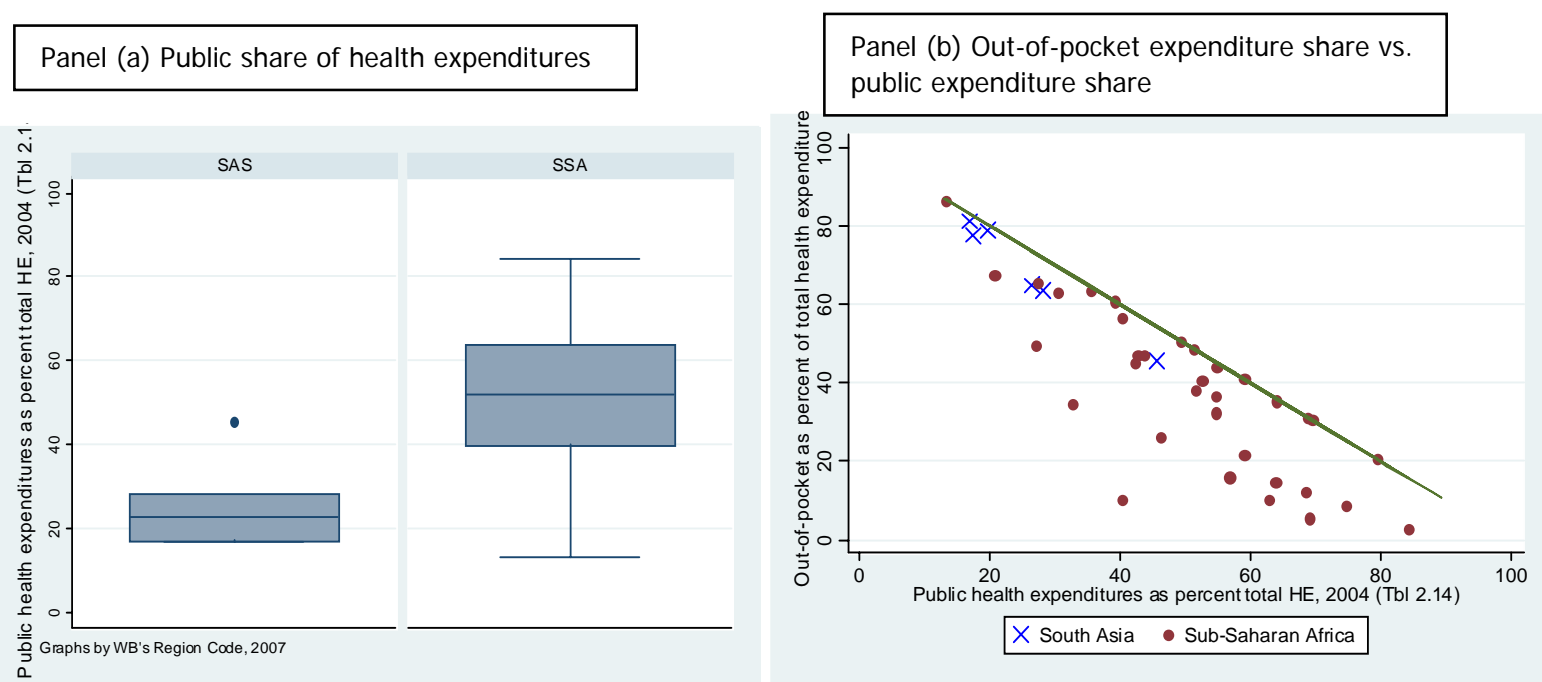

Source: Author's charts from World Bank, 2007.

Whether low public funding makes health care accessible depends on how much of the balance must be covered by the patient out of pocket. Panel $b$ of Figure 6 shows that there is generally a negative relationship between the share of total health expenditure covered by government and the share covered by patients out-of-pocket for both South Asian and 
sub-Saharan countries. ${ }^{7}$ This is not surprising, since the private individual's percentage contribution plus the government's percentage contribution cannot exceed 100. If the government and the private person's out-of-pocket payments were the only contributors to financing health care, all of the countries in both regions would lie exactly on the straight line which is at a 45 degree angle from the two axes. ${ }^{8}$ The reason that the country markers are not on the downward sloping diagonal is that some patients' costs in every country are partly covered by a "third-party payer". These "third-parties" might be public or private insurance schemes or employers. The farther a country marker is to the southwest of the downward sloping straight line, the larger the share that third-party payments assume of the total cost of medical care in that country. For example, the country that is farthest from the diagonal is South Africa, with Botswana, Zimbabwe and Uganda also having substantial coverage of private health expenditure from third party payers. In contrast, none of the South Asian countries benefits from more than 9 percent coverage of health care expenditure by third-party payers. Sri Lanka and Nepal have the most developed health insurance systems, covering about 8.7 percent of total expenditure. In India the coverage of third-party payers in 2004 was only 5.1 percent. $^{9}$

\section{Access to Private Health Care and the Risk of Poverty}

When a household has no access to subsidized public health care and no third-party coverage, it is completely exposed to the possibility of severe sickness episodes and the health care expenses that they entail. Traditional analyses of poverty use household expenditure to gauge the household's well-being. But a household that has experienced lifethreatening illness will sell assets and borrow in order to finance higher-than-normal health care expenditure. Analysis of total household expenditure per capita makes it appear that such a household is doing very well, simply because they spends a lot. Only by netting out the health care expenditure can one approximate the household's actual well-being. To the extent that South Asian AIDS patients are spending out-of-pocket for AIDS treatment, one can surmise that their household expenditure will be similarly inflated.

In studies of a number of European and Asian countries, Adam Wagstaff, Edie Van Doorslaer and their coauthors have developed an interesting graphic technique for displaying the impact on poverty of sickness episodes and the consequent health care

\footnotetext{
${ }^{7}$ To a different degree in each country, the cost of both AIDS and non-AIDS care is currently underwritten by donors. For example, according to India's NACO, the Government of India covers 60 percent of NACO's budget out of either direct budget support or a credit from the World Bank. The remaining 40 percent of NACO's expenditures was funded by grants from DFID, the Global Fund on AIDS, TB \& Malaria and USAID. (http://www.nacoonline.org/About_NACO/Funds_and_Expenditures/)

${ }^{8} \mathrm{~A}$ reviewer points out that the angle may appear different from 45 degrees if the printer chooses an aspect ratio other than one-to-one.

${ }^{9}$ A new initiative entitled the Indian National Health Insurance Program may dramatically increase insurance coverage in India (Range, 2008).
} 
expenditure in the absence of government subsidies or insurance coverage. Figure 8 is reproduced from their analysis of Bangladeshi household expenditure in 2000 where hardly any patients were paying for AIDS treatment. The upward sloping curve displays the cumulative distribution of household expenditure in Bangladesh. The vertical axis measures the household's expenditure per member per day in multiples of the poverty line of US\$1.08 per day. A second horizontal line is constructed at another less-strict poverty line of US\$2.15 per day. The overall distribution shows that according to conventional measures, about $20 \%$ of the Bangladeshi population lived in households where daily consumption was less than US\$1.08 per day and about 70\% lived in households below US\$2.15 per day.

Figure 8. Impact of health expenditure on household net consumption patterns in Bangladesh

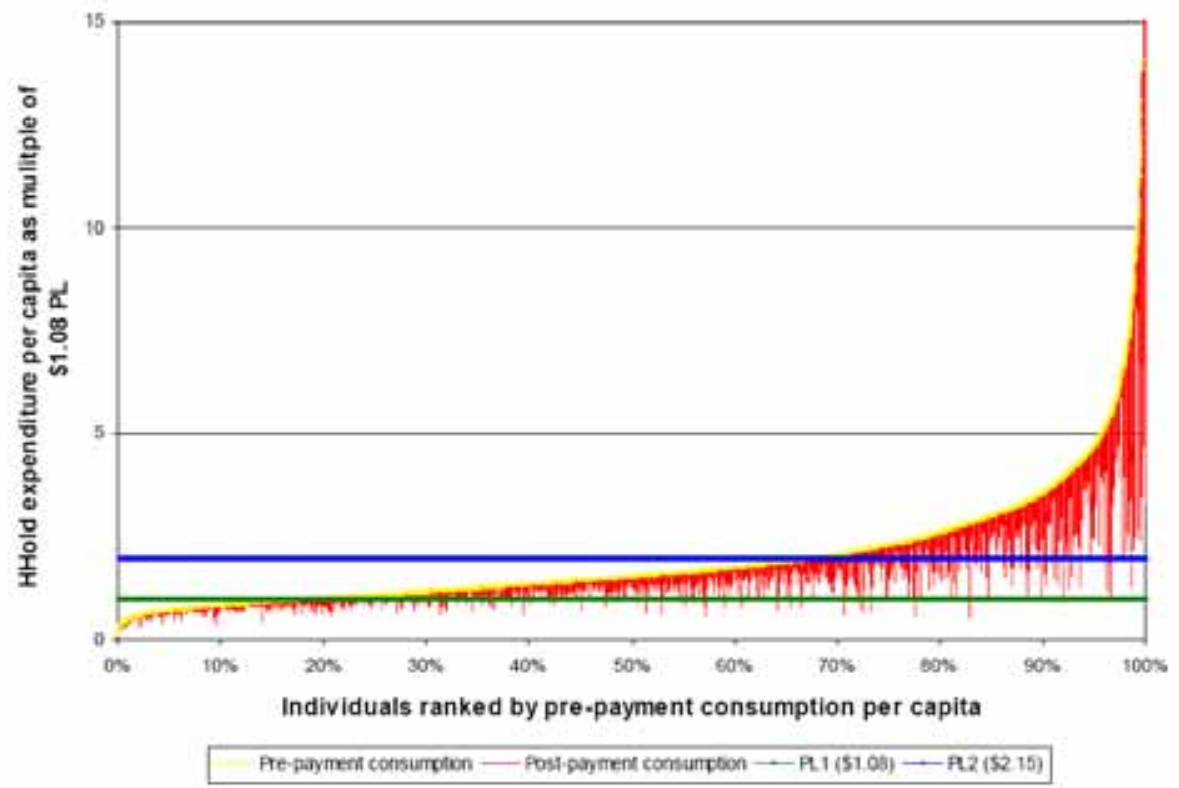

Source: Van Doorslaer and others, 2006. Vertical lines represent reductions in household expenditure per capita caused by health spending: Lines that drop below the poverty line represent individuals pushed into poverty by health expenditure in 2000. 
However, these conventional calculations omit consideration of health expenditure. The downward dropping "paint-drips" from the curved shape of the cumulative expenditure distribution show the effect of subtracting out-of-pocket health expenditure from total expenditure. The impact of this "correction" to the traditional measure of household wellbeing is dramatic for some households, bringing their net consumption per household member below one of the poverty lines. Health expenditure large enough to reduce a family to penury can be fairly classified as "catastrophic". Note that even households that would otherwise have been in the top decile of household expenditure were reduced to poverty by one of the two measures once health expenditure was netted out of their annual consumption. ${ }^{10}$

Figure 8 dramatically depicts the problem of catastrophic health expenditure in Bangladesh, but unavoidably overstates the prevalence of the problem. For one of the vertical "paint-drips" to be visible to the reader, the line must have a certain width. Given the horizontal dimension of the printed page, even a small number of "paint-drips" will occlude the surface of the page, making it look as if virtually all households suffer substantial reductions in well-being from health expenditure. Consequently the only way to assess the prevalence of the problem of catastrophic out-of-pocket health expenditure is to consider a table that gives the percentage of individuals whose household expenditure net of health care costs is in fact below the poverty line.

Table 3, which is excerpted from Van Doorslaer et al (2004), presents the impact on poverty in four South Asian countries of analyzing household expenditure per capita net of health expenditure rather than including it. In India, this re-definition of poverty would push an additional 20.6 million below the higher poverty line and 37.4 million people below the lower one, increasing the proportion of Indian's suffering from the most extreme form of poverty by 12 percent. In Bangladesh, Nepal and Sri Lanka, health expenditure increases the number of those below the lower poverty line by 17, 6 and 8 percent respectively. Although these increases in measured poverty are smaller than might be inferred from Figure 8, they are nevertheless substantial.

Many who have sought private sector treatment for AIDS are likely to have been pushed below the poverty line. Suppose that an individual spends approximately $\$ 365$ a year out-of-

\footnotetext{
${ }^{10}$ The situation is a bit more complex than presented in the text. Since people have insurance and precautionary saving, some of out-of-pocket payments are pre-financed and therefore should not be seen as immiserating. This pre-financed proportion of the OOP payments should instead be subtracted from both gross and net consumption. In Figure 8, this would have the effect of shifting an individual "paint-drip" to the left and also making it shorter. If the slope of the cumulative expenditure curve is sufficiently flat (i.e. less than 45 degrees) such a shift could move an individual who appears to be immiserated by health care expenditures to a position from which health expenditure no longer pushes him or her below the poverty line. See Van Doorslaer, Wagstaff and coauthors for in depth discussion (Van Doorslaer et al. 2007; Van Doorslaer, Wagstaff, and Rutten 1993; Wagstaff 2002; Wagstaff, Van Doorslaer, and Paci 1989).
} 
pocket on AIDS treatment, which is enough to cover the full cost of first-line triple-drug therapy at generic prices plus doctor visits and some laboratory tests. In a four-person household, this would add $\$ 0.25$ per member to daily health expenditure. From Figure 8 we can see that households at about the $40^{\text {th }}$ percentile of Bangladesh's expenditure distribution, which had no other health expenditure, would be pushed down below the lower poverty line by a single AIDS patient, to be on a par with households at the $20^{\text {th }}$ percentile. Two AIDS patients in a household would severely impoverish a household which had previously been at the $45^{\text {th }}$ percentile of the expenditure distribution.

Suppose that the distributions of overall expenditure and health expenditure for the poorest 40 percent of the Indian population are similar to those of the lowest 40 percent of the Bangladeshi population as depicted in Figure 8. Further suppose that all of the estimated 500,000 to $1,600,000$ people who are estimated to be living with AIDS in India are in households which would otherwise be above the $\$ 1.08$ poverty line, but not above the $40^{\text {th }}$ percentile of the Indian income distribution. Since there were between $\$ 300$ and $\$ 500$ million Indians living under the $\$ 1.08$ poverty line in 2000 , AIDS would increase the number of strictly poor by less than half of a percent. In so doing it would increase the percentage of the population below the stricter poverty line by about 3 percent, from about 35 percent to 38 percent.

Table 3. Poverty head counts: effect of accounting for out-of-pocket payments for health care, various years

Poverty line of $\$ 1.08$ per day

Change in poverty head count

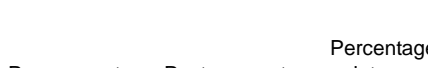

Prepayment Postpayment head count* head count

Bangladesh

India

Nepal

Sri Lanka

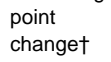

$0.3 \%$

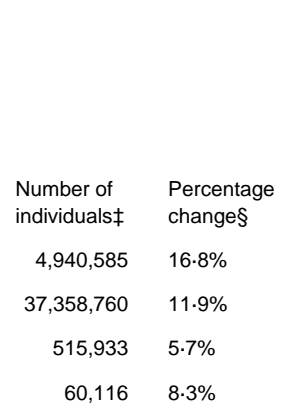

$60,116 \quad 8.3 \%$
Poverty line of $\$ 2 \cdot 15$ per day

Change in poverty head count

$\begin{array}{lll}\begin{array}{l}\text { Prepayment } \\ \text { head count* }\end{array} & \begin{array}{l}\text { Postpayment } \\ \text { head count }\end{array} & \begin{array}{l}\text { Percentage } \\ \text { point } \\ \text { change }\end{array} \\ 73 \cdot 0 \% & 76 \cdot 5 \% & 3.6 \% \\ 80.3 \% & 82.4 \% & 2.1 \% \\ 80.4 \% & 81.7 \% & 1.3 \% \\ 39.1 \% & 40.8 \% & 1.7 \%\end{array}$

Number of individuals $\ddagger$ $4,653,875$ 20,638,361 290,280 $325,783 \quad 4 \cdot 3 \%$

This analysis does not take into account the fact that AIDS treatment must continue for the rest of the patient's life. Most of the "paint-drips" in Figure 8 are probably associated with acute illness, not with chronic illness. A household might recover its economic status after a single catastrophic expenditure depresses their net expenditure for a single year. But that same household would need more robust coping strategies to deal with a stream of catastrophic expenditures over several years. To analyze chronic disease, one would need a graph like Figure 8 which would be constructed for wealth (or "permanent income") instead of expenditure.

In order to push this analysis further, it would be useful to have information on the distribution of South Asian HIV infections across the income or expenditure distributions depicted in graphs like Figure 8. Reports of mostly poor people accessing government 
subsidized antiretroviral therapy in the last few years can be set against anecdotes and rumors about the spread of AIDS among the relatively wealthy in Bollywood. Unfortunately until recently there has been no population-based information available on the distribution of HIV infection by socioeconomic class, in India or indeed in almost any country in the world. ${ }^{11}$ The fact that India's recent reassessment of the extent of HIV infection was based on a household survey offers hope that India will be able to correlate HIV infection to socioeconomic status for the first time.

Even without data on the socioeconomic distribution of HIV infection in South Asia, the absence of either a large public presence in health care delivery or significant health insurance coverage for nineteen out of twenty South Asian citizens renders the population unusually vulnerable to the financial risk of catastrophic health expenditures to treat AIDS. The efforts by governments in the region to assume public sector responsibility for rolling out AIDS treatment is a movement against the trend towards private sector dominance in the health care market. The next section presents projections of the accumulating number of patients needing treatment and poses the question of whether the government subsidized care can grow fast enough to meet all of that demand.

\section{Quality of Private vs. Public ART}

The consequences for the quality and availability of AIDS treatment of a major private sector role in AIDS health care delivery in poor countries are largely unknown. One view is that the newer formulations of antiretroviral drugs are so inexpensive, convenient and easy to understand that private sector care might be as high in quality as public sector care and might extend treatment access to many people who could not otherwise obtain it in the South Asian countries. An alternative view is that private providers have insufficient incentive to support patient adherence to the drug regimen, without which the treatment will fail, and the patient may transmit a resistant form of HIV and then die. The worst possibility is that private sector distribution would expand rapidly in the form of casual overthe-counter sales of a heterogeneous and fluctuating mixture of full-strength, diluted and counterfeit antiretroviral medications, without any prescription or medical supervision. This kind of private sector expansion is a recipe for exacerbating both the spread and the cost of the AIDS epidemic. Within the complex private health care sectors in South Asian countries there are surely examples of both adherence maximizing and adherence minimizing private care. The heterogeneity of private care between these two extremes remains to be determined. Of course, similar questions can also be raised about the quality of public sector care.

\footnotetext{
${ }^{11}$ An early challenge to the assumption that HIV prevalence would be higher among the poor or uneducated is presented in Ainsworth \& Over (1997). The incorporation of blood tests into general purpose national surveys have shown that the highest HIV prevalence levels are often at mid or even at the highest levels of socioeconomic status in African countries (Montana, Neuman, Mishra and Macro International, 2007; Barnighausena, Hosegooda, Timaeus and Newella, 2007).
} 
To the extent that private care is less successful at supporting patient adherence to ART regimes than is the average public care facility, public financing of public sector ART delivery can be seen as crowding out some of the private sector care. If public sector care is less expensive to the patient than private care, and patients have at least a little knowledge of the relative merits of different service providers, the public sector care will be crowding out the worst of the private care, and thus preserving patient lives while stemming the development and spread of resistant strains of HIV.

The possibility that publicly provided AIDS treatment might crowd out lower quality private care is an unusual and notable feature of public sector AIDS treatment in South Asia. ${ }^{12}$ Usually when public subsidy or subsidized provision of a good or service crowds out private provision, any redistributive benefits that accrue must be weighed against the consequent efficiency losses. In this case, assuming that the public sector succeeds more than the lowquality private sector at facilitating patient adherence, the crowding out is preventing negative spillovers and is thus contributing to an improvement in efficiency. Given the right magnitudes for these various effects, crowding-out could provide a sufficient justification for public financing and provision even in the absence of the distributive arguments.

Model delivery of ART includes the following essential components: (i) standardized, competency-based, training of physicians in ART management; (ii) prescription of a standard triple-drug regimen; (iii) support from a multidisciplinary team including a counselor and a nutritionist; (iv) regular clinical and laboratory-based monitoring of the patient's treatment status; (v) counseling to prevent transmission; (vi) prophylaxis for opportunistic illnesses when indicates; and (vii) diagnosis and treatment of opportunistic illnesses (Over and others, 2006). Thus, the question of whether private sector delivery of ART would improve or worsen the quality of care in South Asia, depends on what proportion of the privately delivered ART meets these criteria.

In previous work, this author and his co-authors have conjectured that the private sector care used by India's poorest AIDS patients would be "unstructured" in the sense that it would not typically include these seven essential components and have modeled the impact of these assumptions on the future fiscal burden of AIDS treatment in that country

\footnotetext{
${ }^{12}$ Deolaliker and others (2008) argue that public spending on any type of health care can achieve equity goals by crowding out private out-of-pocket spending by the poor. However, they also say that "[i]ncreasing public spending on health can be justified only if it yields health benefits" (ibid, $p$. 980). This would only be the case if public sector health spending improves health status enough to more than offset the reduction in health status due to the crowding out of private health spending. Whether publicly financed or provided health care is much more effective than privately financed or delivered care will depend a great deal on the context, but it might be especially true for services delivered to the poor and uneducated which generate negative spillovers when incompetently performed. The efficiency argument for public intervention to assure the quality of health care delivery is thus particularly strong for diseases like AIDS, TB and malaria for which low quality treatment accelerates the development and spread of drug resistance.
} 
(Over and others, 2004). Since the publication of that book, only a single study has been published that addresses this conjecture. Sheikh and coauthors interviewed 215 providers in Pune, India and found that three-quarters of them had been consulted by HIV-infected clients. Of these, 14 percent had prescribed ART, "sometimes without adequate knowledge of the guidelines for their use" (Sheikh and others, 2005).

On the other hand, it is not clear that public sector ART programs will necessarily be of higher quality. One study analyzed the treatment of 32 HIV/AIDS patients prior to 2004 at the B. P. Koirala Institute of Health Sciences, a major teaching hospital in eastern Nepal (Shrestha, Bhatta, and Bhatta, 2006). Thirteen of these were discharged with virtually no care. Among the rest, six of the seven OI prescriptions and all of the four ART prescriptions were incorrect. The authors concluded that "the care of HIV-infected patients even at a major tertiary care teaching hospital in Nepal [was] sub-optimal." Since the Nepalese government has invested in the expansion of ART since 2003, a new study would hopefully reveal substantial improvement.

In a study of the quality of the delivery of general outpatient medical services (where there was no HIV diagnosis), Das and Hammer found that quality was extremely variable in the public as well as the private programs (Das and Hammer 2004). But deviations from best practice care occurred in different directions and for different reasons in the two sectors. According to the authors, "[i]n the public sector providers are more likely to commit errors of omission - they are less likely to exert effort compared with their private counterparts. In the private sector, providers are prone to errors of commission - they are more likely to behave according to the patient's expectations, resulting in the inappropriate use of medications, the overuse of antibiotics, and increased expenditures".

Both types of errors, of omission or commission, threaten the quality and therefore the success of AIDS treatment in India. Either can lead to early treatment failure for the patient and transmission by the patient of a drug resistant strain of HIV to someone who consequently requires much more expensive second-line or salvage drug therapy. Thus, a government that is committed to providing subsidized AIDS treatment to all has an important role to play in assuring minimum quality standards for AIDS care in the private as well as the public sector. ${ }^{13}$

\section{Conclusions}

To the extent that patients seek out and obtain good quality AIDS treatment from the private sector, South Asian governments can achieve the benefits of rapid scale up without directly bearing the costs. However, it is difficult to project what the share of private treatment is now or will be in the future. If HIV infections are evenly distributed across the

${ }^{13}$ High quality AIDS treatment will not only maximize adherence, and thus patient survival, but will also minimize transmission in the community through outreach programs. Potential mechanisms to achieve this goal are discussed in Over and others (2006) and Over and others (2007). 
range of South Asian living standards, then only 30 percent of the cases would be above the more generous poverty line of US\$2.15. And the poorest 10 percent of these (the third decile of the expenditure distribution) would be pushed down into poverty by AIDS treatment expenditures. Under these assumptions, only 20 percent of AIDS patients could afford to pay for treatment without becoming impoverished. Without government subsidy, AIDS treatment would be beyond the reach of 80 percent of patients.

Against this background, the South Asian governments have three choices. They can strive to meet the goal of universal access as best they can with public delivery of ART. This policy will lead to the greatest expansion in costs and incidentally will swim against the current of the increasing privatization of South Asian health services. ${ }^{14}$ They can allow the expansion of private AIDS care for those who can afford it, while trying to reduce its cost and assure its quality. Or they can use the AIDS epidemic as one more incentive to push for greater health insurance and other third-party payment of health care costs. The latter policy would be difficult to follow in a population with extremely high prevalence rates, because AIDS treatment is an expensive risk and would raise issues of adverse selection. But a policy to expand health insurance which includes coverage of AIDS treatment may succeed in India and other South Asian countries where a diagnosis of HIV positive is still relatively rare. For example, India could experiment with adding AIDS treatment to its recently launched National Health Insurance Program, provided that the government authorizes the reimbursement of antiretroviral medication when delivered by providers who have received accredited training in that specialization and submit to rigorous periodic supervision (Range, 2008). ${ }^{15}$

Whether or not the South Asian governments decide to explicitly encourage private sector delivery of AIDS care, they have a fundamental responsibility to collect data on the quality of both public and private AIDS care. Only through data collection on both types of AIDS care will it be possible to gauge the quality difference between the local public and private delivery systems. Since private providers may have little incentive to retain clients over the many months and then years required for treating this chronic illness, regulation of the private AIDS treatment sector is recommended. Depending on the findings of such a data collection and monitoring project the government could decide to accelerate public

\footnotetext{
${ }^{14}$ A reviewer points out that the government of India has recently committed to increasing health expenditure from its present 1 percent of GDP to $2-3$ percent of GDP by 2012. This paper shows that expansion of AIDS treatment could potentially absorb all of such an increase.

${ }^{15}$ Provided that HIV infection remains rare, enrollees are risk adverse and enrollment procedures in the new National Health Insurance Program effectively minimize adverse selection into the program of those who are more likely to be HIV infected, inclusion of ART could enhance the consumer surplus provided by the program's benefit package by more than it increases its costs. Thus it would be efficient as well as equitable to cover ART with insurance. In contrast, an analysis along costeffectivness lines such as that in Deolaliker and others (2008) would exclude ART as less costeffective than other interventions.
} 
provision (in order to crowd out the lowest end of the AIDS care spectrum) or to develop explicit strategies for delegating a part of the care burden to the private sector. It might be necessary to do both, each with a different segment of the private market. 


\section{References}

Barnighausena, T, Hosegooda, V, Timaeusa, I and Newella, M-L. 2007. The socioeconomic determinants of HIV incidence: evidence from a longitudinal, population-based study in rural South Africa. AIDS. Vol 27, Suppl. 7. pp: S29-S38

Ainsworth, M and Over, M. 1997. Confronting AIDS: Public priorities in a Global Epidemic. Washington, DC: World Bank.

Claeson, M, and Haacker, M. 2009. HIV/AIDS as an Economic Development Risk in South Asia, Washington, DC: World Bank.

Das J, and Hammer JS. 2004. Strained Mercy: The Quality of Medical Care in Delhi. SSRN elibrary.

Deolalikar, A, Jamison, D, Prabhat, J and Laxminarayan, R. 2008. Financing Health Improvements In India. Health Affairs, Vol. 27, no. 4, pp. 978-990

Hira, Subhash K., 2003, "ART Prescribing Physicians in India," background paper to Over and others, 2004.

Montana, L, Neuman, M, Mishra, V, Macro International Inc. 2007. Spatial Modeling of HIV Prevalence in Kenya. WP27, Calverton, MD: Macro International.

Over, M. 2004. Impact of the HIV/AIDS epidemic on the health sectors of developing countries. In The macroeconomics of HIV/AIDS. Edited by Markus Haacker. Washington, D.C.: International Monetary Fund.

Over, M. 2008. Prevention Failure: The Ballooning Entitlement Burden of U.S. Global AIDS Treatment Spending and What to Do About It. Working Paper \#144. Washington, DC: Center for Global Development.

Over M, Marseille E, Sudhakar K, Gold J, Gupta I, Indrayan A, Hira S, Nagelkerke N, Rao AS, and Heywood P. 2006. Antiretroviral therapy and HIV prevention in India: modeling costs and consequences of policy options. Sex Transm. Dis. 33 (10 Suppl): S145-S152.

Over M, Revenga A, Masaki E, Peerapatanapokin W, Gold J, Tangcharoensathien V, and Thanprasertsuk S. 2007. The economics of effective AIDS treatment in Thailand. AIDS 21 Suppl 4: S105-S116.

Over M, Heywood P, Marseille E, Gupta I, Hira S, Nagelkerke N, and Rao AS. 2004. HIV/AIDS treatment and prevention in India: modeling the costs and consequences. Washington, DC: World Bank.

Peters, David H., Abdo S. Yazbeck, Rashmi R. Sharma, G.N.V. Ramana, Lant H. Pritchett and Adam Wagstaff, 2002, A Better Health Systems for India's Poor: Findings, Analysis, and Options (Washington D.C.: World Bank).

Range, J. 2008. India's poor get health care in a card. Wall Street Journal Online, accessed February 22, 2009. http://online.wsj.com/article/SB121971773721671817.html

Sengupta A, Nundy S. The private health sector in India. British Medical J ournal 2005;331:1157-8. 
Sheikh K, Rangan S, Deshmukh D, Dholakia Y, and Porter J. 2005. Urban private practitioners: potential partners in the care of patients with HIV/AIDS. Natl. Med. J. India 18 (1): 32-36.

Shrestha NK, Bhatta Na, and Bhatta N. 2006. Current status of inpatient HIV care at a tertiary care center in Nepal. Scandinavian Journal of Infectious Diseases 38: 366-370.

Steinbrook, Robert, 2007, "HIV in India - The Challenges Ahead," New England J ournal of Medicine, Vol. 356, No. 12, pp. 1197-201.

van Doorslaer, E., and others, 2006, "Effect of payments for health care on poverty estimates in 11 countries in Asia: an analysis of household survey data," The Lancet, Vol. 368, No. 9544, pp. 1357-64.

Van Doorslaer E, and others, 2007, "Catastrophic payments for health care in Asia," Health Econ. 16 (11): 1159-1184.

Van Doorslaer E, Wagstaff A, and Rutten FFH. 1993. Equity in the finance and delivery of health care: an international perspective. Oxford: Oxford University Press.

Wagstaff A. 2002. Inequalities in health in developing countries: swimming against the tide? Washington, D.C: World Bank, Development Research Group, Public Services, and, Human Development Network, Health, Nutrition, and Population Team.

Wagstaff A, Van Doorslaer E, and Paci P. 1989. Equity in the finance and delivery of health care: some tentatuive cross-country comparisons. Oxford Review of Economic Policy 5 (1): 89-112.

World Bank, 2007, World Development Indicators (Washington DC: World Bank).

World Health Organization (WHO), J oint United Nations Programme on HIV/AIDS, and United Nations Children's Fund (WHO, UNAIDS, and UNICEF), 2007, "Towards Universal Access - Scaling up Priority HIV/AIDS Interventions in the Health Sector" (Geneva and New York: WHO, UNAIDS, and UNICEF).

World Health Organization (WHO), Joint United Nations Programme on HIV/AIDS, and United Nations Children's Fund (WHO, UNAIDS, and UNICEF), 2008, "Towards Universal Access - Scaling up Priority HIV/AIDS Interventions in the Health Sector" (Geneva and New York: WHO, UNAIDS, and UNICEF). 
Annex 1. Proj ected fi sCal buRden of AI DS tReatment in Four South Asi An Countri es ${ }^{16}$

$\mathrm{BGD}=$ Bangladesh, $\mathrm{BTN}=$ Bhutan, $\mathrm{LKA}=$ Sri Lanka, PAK=Pakistan

AIDS Treatment: Numbers, costs \& entitlement Total for country BGD
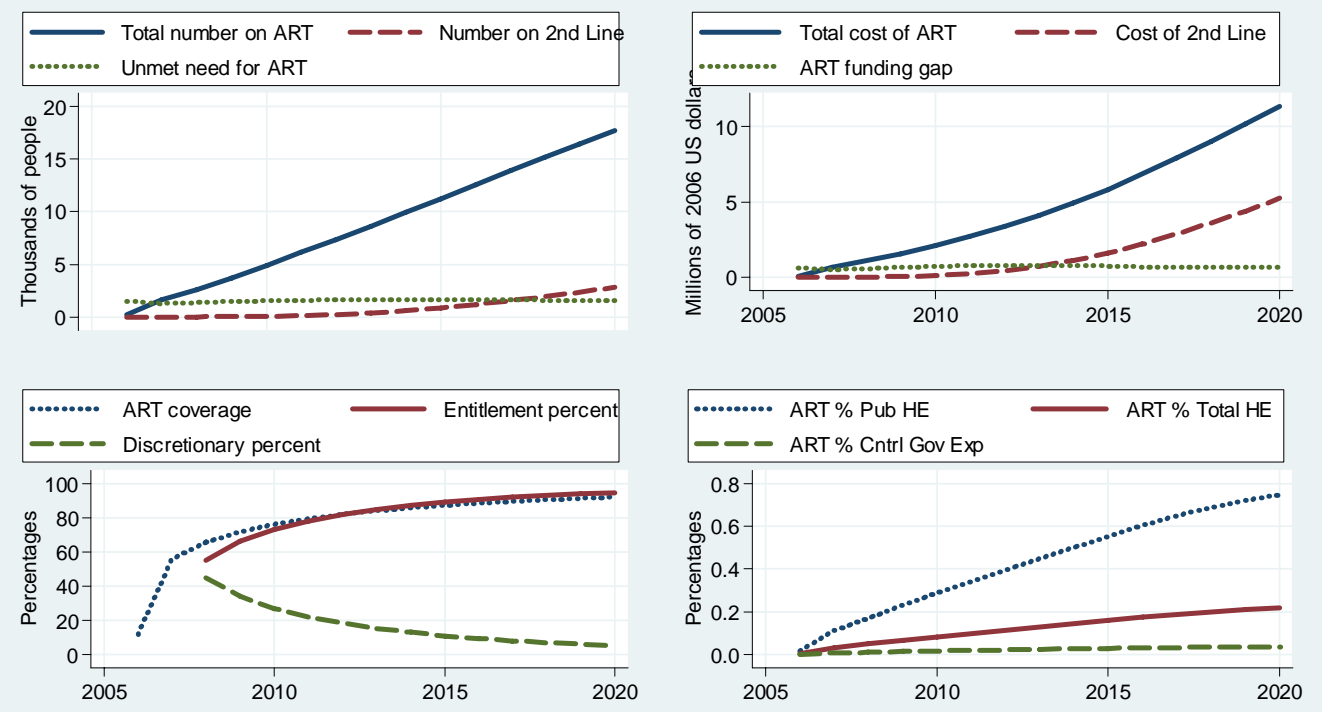

Adjusting at $95.0 \%$ of unmet need each year

adrate $1=.13$, adrate $2=.04$, bdrate $=.01$, Erate $=.11$, ndrate $=.3$, incdwn $=.95$

\footnotetext{
${ }^{16}$ In the southwest panel of each figure the term "entitlement" refers to that portion of total expenditures in any given year that sustains patients who have survived on treatment from a previous year, while the term discretionary refers to expenditures on patients newly recruited to treatment in the current year. See Over (2008) for a discussion of this terminology as applied to the United States' PEPFAR program.
} 


\section{AIDS Treatment: Numbers, costs \& entitlement Total for country BTN}
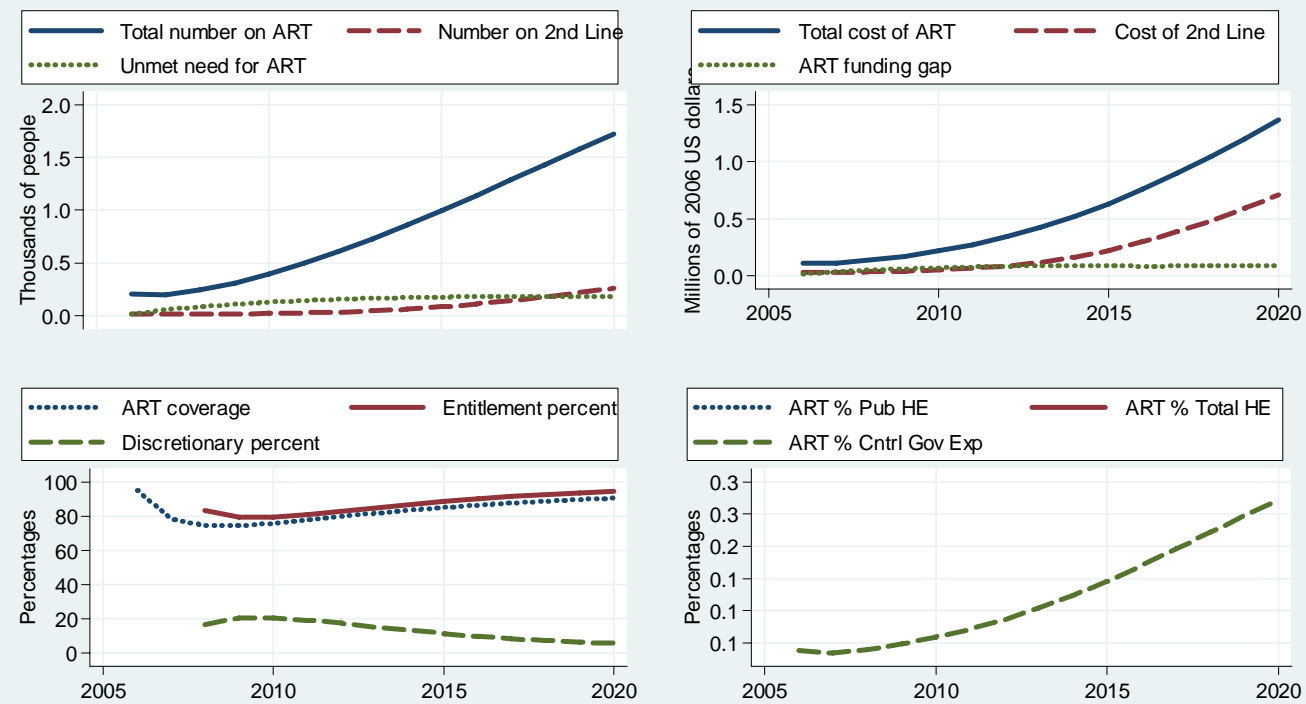

Adjusting at $95.0 \%$ of unmet need each year

adrate $1=.13$, adrate $2=.04$, bdrate $=.01$, Erate $=.11$, ndrate $=.3$, incdwn $=.95$

\section{AIDS Treatment: Numbers, costs \& entitlement} Total for country LKA
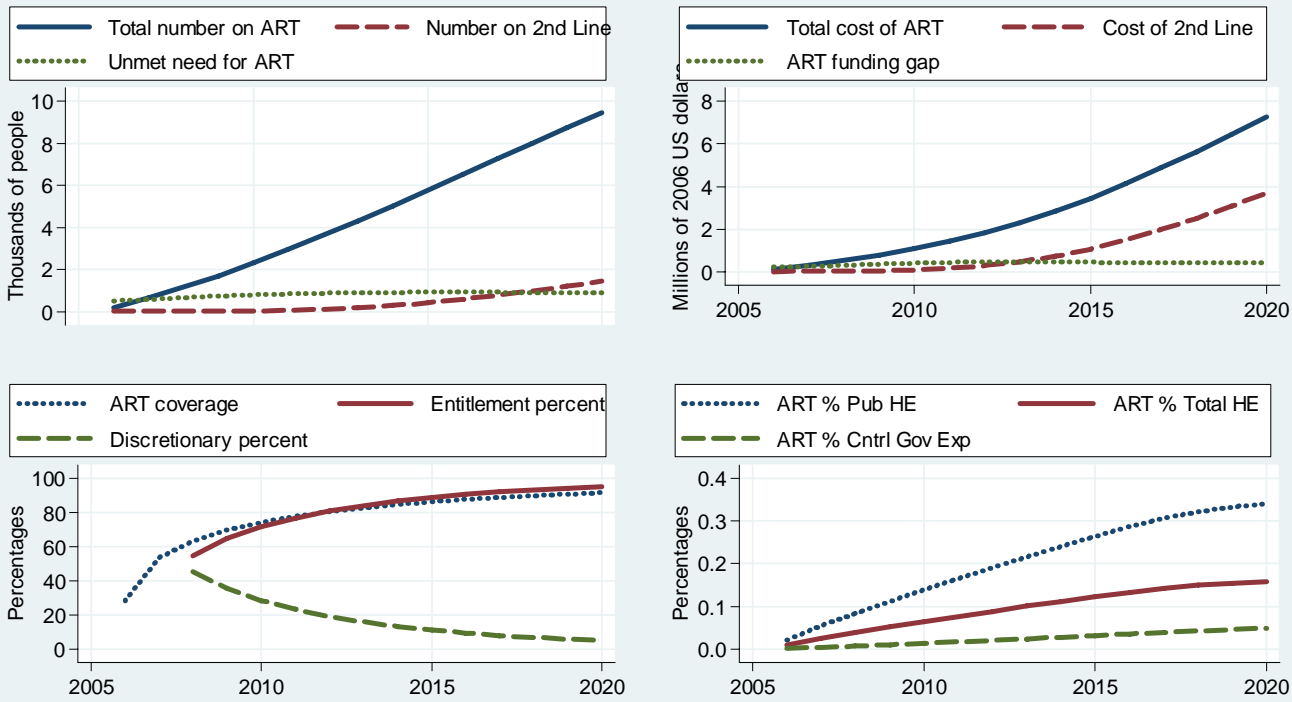

Adjusting at $95.0 \%$ of unmet need each year

adrate $1=.13$, adrate $2=.04$, bdrate $=.01$, Erate $=.11$, ndrate $=.3$, incdwn $=.95$ 
AIDS Treatment: Numbers, costs \& entitlement Total for country PAK
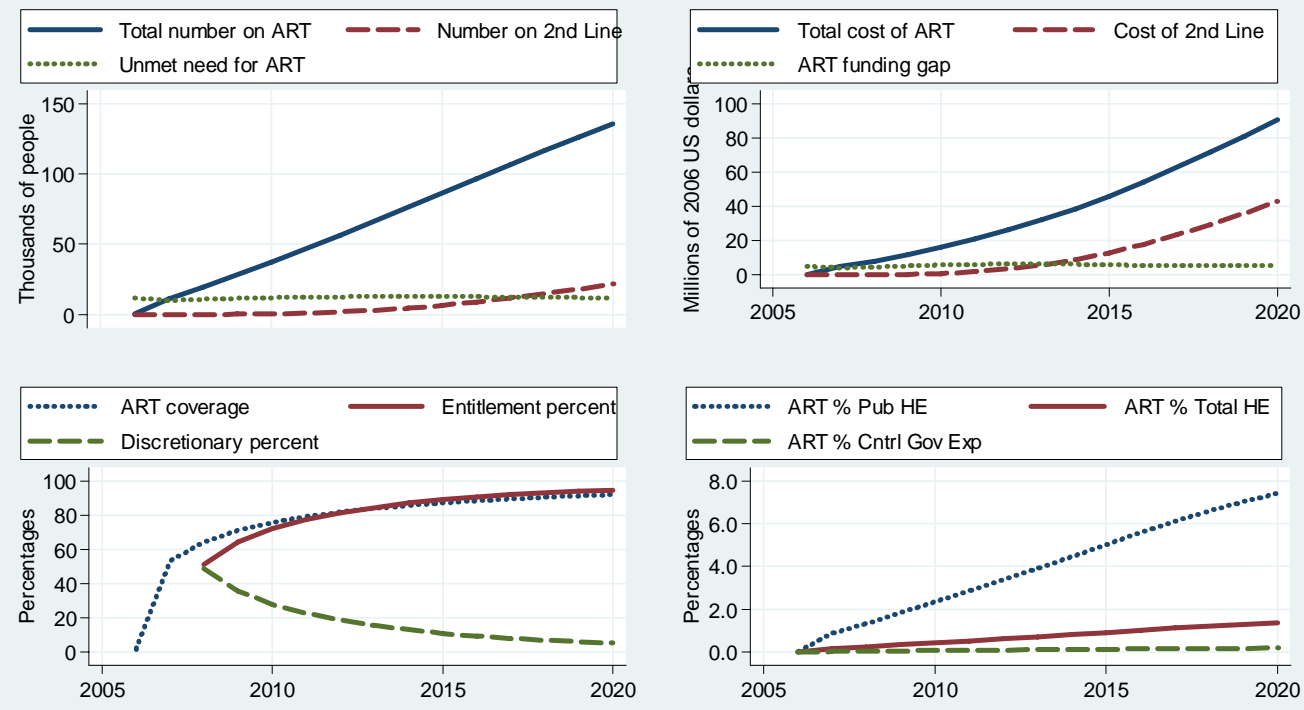

Adjusting at $95.0 \%$ of unmet need each year

adrate $1=.13$, adrate $2=.04$, bdrate $=.01$, Erate $=.11$, ndrate $=.3$, incdwn $=.95$ 


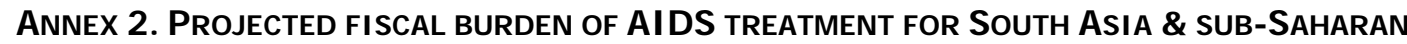 AFRICA}

AIDS Treatment: Numbers, costs \& entitlement Total for region SAS
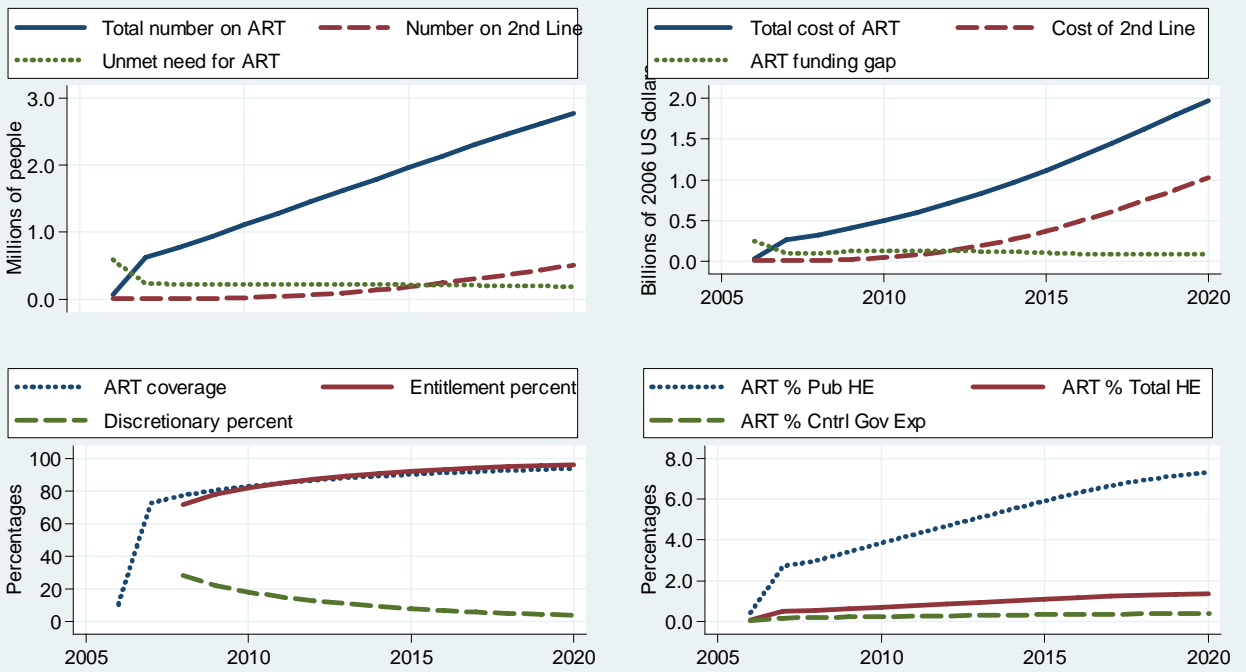

Adjusting at $95.0 \%$ of unmet need each year adrate $1=.13$, adrate2 $=.04$, bdrate $=.01$, Erate $=.11$, ndrate $=.3$, incdwn $=.95$

AIDS Treatment: Numbers, costs \& entitlement Total for region SSA
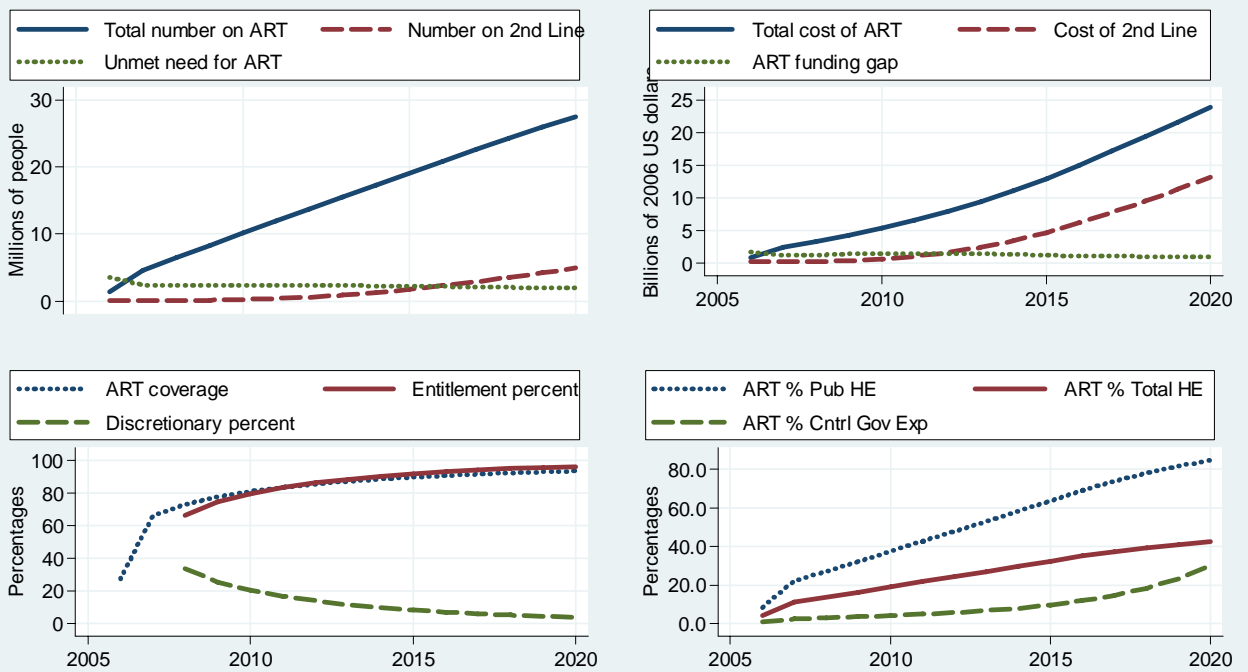

Adjusting at $95.0 \%$ of unmet need each year adrate $1=.13$, adrate2 $=.04$, bdrate $=.01$, Erate $=.11$, ndrate $=.3$, incdwn $=.95$ 


\section{ANNEX 3. A MODEL FOR PROJ ECTI NG FUTURE AI DS TREATMENT COSTS ${ }^{17}$}

Projections of future treatment costs were made using a simple difference equation model based on those used in previous modeling studies of AIDS treatment in India (Over et al. 2004) and Thailand (Over et al. 2006). The prototype model was developed using Modelmaker from ModelKinetix (http://www.modelkinetix.com/) and then ported to STATA. The STATA code is available from the author on request.

The following figure provides a flow diagram of the model's difference equations as implemented by the STATA program aidsproj.ado. The dark lines with arrow heads indicate flows from a source to a sink. Parameter names close to those arrow heads are defined below the figure. Most of them are annual rates of flow expressed as proportions of the source population that move towards the sink in a single year. However, the parameter "Cvrg2" represents the proportion of patients needing second line therapy who gain access to it in a given year. The runs of the model reported here assume that coverage with second-line therapy starts at 5 percent of those needing it in 2006 and levels off at 95 percent of those needing it in 2016.

Flow diagram for aidsproj model predicting the future growth of AIDS treatment costs

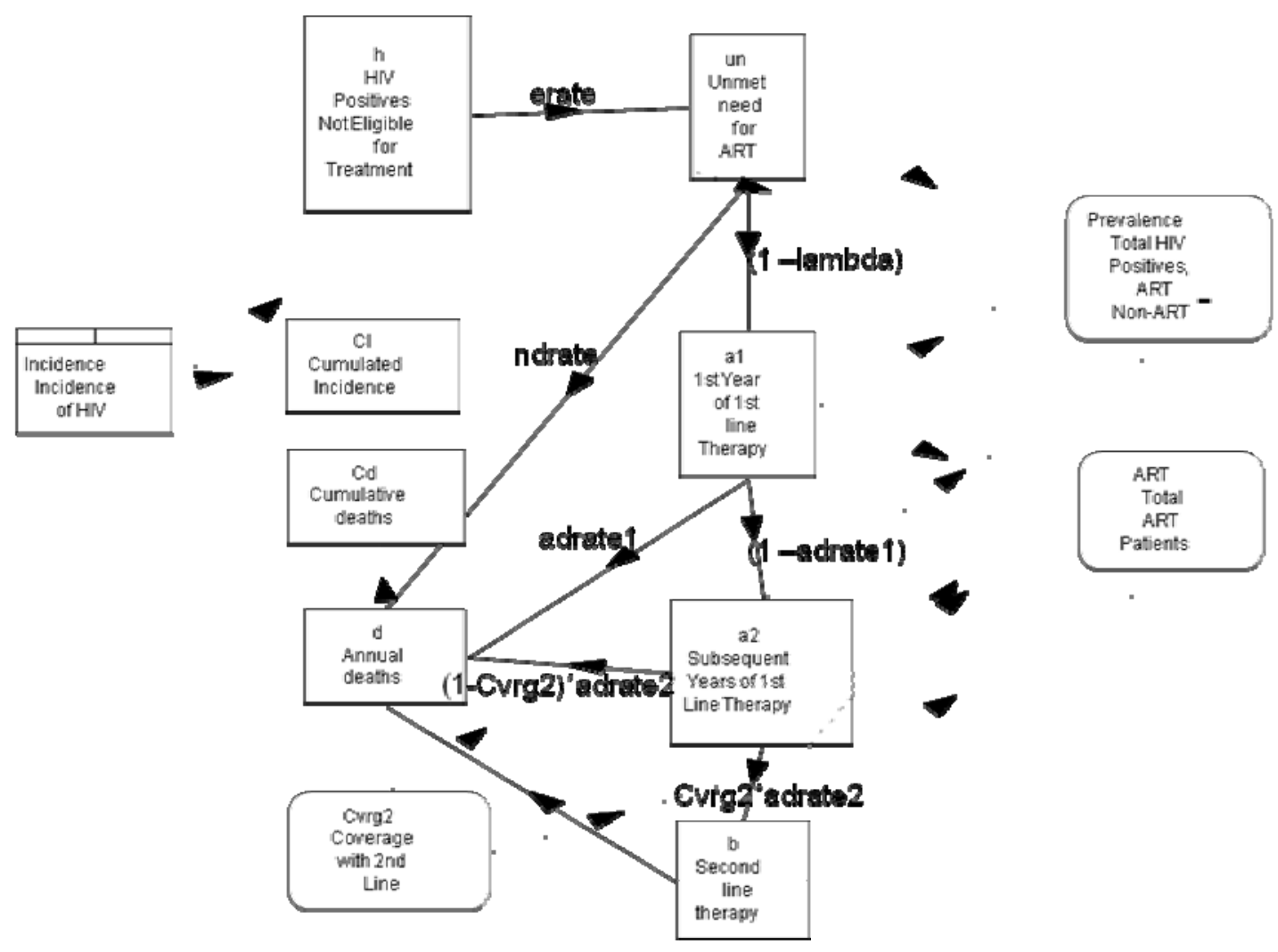

${ }^{17}$ See the Spectrum projection model for an alternative approach: http://www. futuresinstitute.org/. 


\section{Parameters of the aidsproj projection model}

Proportion of HIV+ newly eligible for ART ART Death Rate during first year on 1st line ART Failure Rate during subsequent years on 1st line ART Death Rate of AIDS patients on 2nd line Non-ART Death Rate of AIDS patients

Starting coverage rate for 2 nd line $A R T^{18}$

Target coverage rate for 2 nd line ART

$\begin{array}{ll}\text { erate } & .11 \\ \text { adrate1 } & .13 \\ \text { adrate2 } & .04 \\ \text { bdrate } & .01 \\ \text { ndrate } & .3 \\ \text { strtcov2 } & .05 \\ \text { trgtcov2 } & .95 \\ \text { trgtyr } & 2016\end{array}$

Scale-up of 1st line modeled as constant proportion ( 1 - lambda) of unmet need, where lambda is constant across all countries and equal to:

Historical scale up lambda $=\quad .82$

Rapid scale up

Annual cost per patient of first-line drugs ${ }^{19}$ lambda $=\quad .05$

Annual cost per patient of second-line drugs

Annual cost per patient of clinic time
$\$ 227$

$\$ 2,681$

$\$ 278$

\footnotetext{
${ }^{18}$ The model embodies the assumption that, for those people who fail first-line ART, access to second-line ART expands along a logistic curve from about 5 percent of all patients needing it now to $95 \%$ of all patients needing it in 2016.

${ }^{19}$ Drug costs are assumed to vary across countries with the 2006 GDP per capita of the country according to the patterns observed by WHO in that year and then to remain constant (in constant dollars) in any given country over time. While the costs of drugs may be reduced as markets for antiretroviral drugs become more contestable, the unit costs of achieving high ART uptake and strong adherence may increase at the same rate, leaving average costs per patient unchanged.
} 


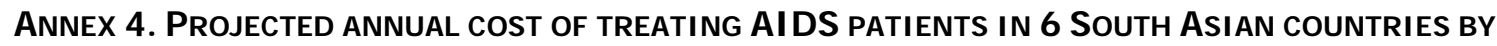 UPTAKE AND PREVENTI ON SCENARI OS (2006 US DOLLARS)}

\begin{tabular}{|c|c|c|c|c|c|c|c|}
\hline & \multicolumn{3}{|c|}{$\begin{array}{l}\text { Costs of AIDS treatment at historical } \\
\text { uptake with effective prevention } \\
\text { (90\% reduction in incidence each year) }\end{array}$} & & \multicolumn{3}{|c|}{$\begin{array}{l}\text { Costs of AIDS treatment at historical } \\
\text { uptake with moderate prevention } \\
\text { ( } 5 \% \text { reduction in incidence each year) }\end{array}$} \\
\hline & 1st line & 2nd line & Total cost & & 1st line & 2nd line & Total cost \\
\hline 2006 & 26,991 & 7,673 & 34,664 & 2006 & 26,991 & 7,673 & 34,664 \\
\hline 2007 & 40,188 & 8,071 & 48,259 & 2007 & 40,188 & 8,071 & 48,259 \\
\hline 2008 & 52,467 & 9,102 & 61,569 & 2008 & 52,467 & 9,102 & 61,569 \\
\hline 2009 & 64,405 & 11,313 & 75,718 & 2009 & 64,405 & 11,313 & 75,718 \\
\hline 2010 & 75,425 & 15,087 & 90,512 & 2010 & 76,001 & 15,087 & 91,088 \\
\hline 2011 & 85,236 & 20,780 & 106,016 & 2011 & 87,218 & 20,780 & 107,998 \\
\hline 2012 & 93,718 & 28,679 & 122,397 & 2012 & 98,019 & 28,734 & 126,753 \\
\hline 2013 & 100,865 & 38,979 & 139,844 & 2013 & 108,363 & 39,270 & 147,633 \\
\hline 2014 & 106,732 & 51,806 & 158,538 & 2014 & 118,206 & 52,677 & 170,883 \\
\hline 2015 & 111,410 & 67,205 & 178,615 & 2015 & 127,511 & 69,213 & 196,724 \\
\hline 2016 & 115,008 & 85,176 & 200,184 & 2016 & 136,255 & 89,109 & 225,364 \\
\hline 2017 & 117,630 & 103,798 & 221,428 & 2017 & 144,420 & 110,451 & 254,871 \\
\hline 2018 & 119,396 & 122,889 & 242,285 & 2018 & 151,987 & 133,122 & 285,109 \\
\hline 2019 & 120,401 & 142,267 & 262,668 & 2019 & 158,953 & 157,014 & 315,967 \\
\hline 2020 & 120,747 & 161,774 & 282,521 & 2020 & 165,319 & 182,005 & 347,324 \\
\hline Total & $1,350,619$ & 874,599 & $\begin{array}{r}\text { Least costly } \\
2,225,218 \\
\end{array}$ & Total & $1,556,303$ & 933,621 & $2,489,924$ \\
\hline & \multicolumn{3}{|c|}{$\begin{array}{l}\text { Costs of AIDS treatment at rapid uptake } \\
\text { with effective prevention } \\
\text { (90\% reduction in incidence each year) }\end{array}$} & & \multicolumn{3}{|c|}{$\begin{array}{l}\text { Costs of AIDS treatment at rapid uptake } \\
\text { with moderate prevention } \\
\text { (5\% reduction in incidence each year) }\end{array}$} \\
\hline & 1st line & 2nd line & Total cost & & 1st line & 2nd line & Total cost \\
\hline 2006 & 26,991 & 7,673 & 34,664 & 2006 & 26,991 & 7,673 & 34,664 \\
\hline 2007 & 258,193 & 8,071 & 266,264 & 2007 & 258,193 & 8,071 & 266,264 \\
\hline 2008 & 319,797 & 9,102 & 328,899 & 2008 & 319,797 & 9,102 & 328,899 \\
\hline 2009 & 388,257 & 23,025 & 411,282 & 2009 & 388,257 & 23,025 & 411,282 \\
\hline 2010 & 445,754 & 46,425 & 492,179 & 2010 & 455,046 & 46,425 & 501,471 \\
\hline 2011 & 492,955 & 81,134 & 574,089 & 2011 & 519,393 & 81,134 & 600,527 \\
\hline 2012 & 531,116 & 128,198 & 659,314 & 2012 & 580,896 & 129,118 & 710,014 \\
\hline 2013 & 561,384 & 188,133 & 749,517 & 2013 & 639,259 & 192,155 & 831,414 \\
\hline 2014 & 584,774 & 261,115 & 845,889 & 2014 & 694,262 & 271,843 & 966,105 \\
\hline 2015 & 602,187 & 347,036 & 949,223 & 2015 & 745,756 & 369,568 & $1,115,324$ \\
\hline 2016 & 614,414 & 445,581 & $1,059,995$ & 2016 & 793,646 & 486,518 & $1,280,164$ \\
\hline 2017 & 622,159 & 546,294 & $1,168,453$ & 2017 & 837,891 & 611,374 & $1,449,265$ \\
\hline 2018 & 626,036 & 648,227 & $1,274,263$ & 2018 & 878,483 & 743,426 & $1,621,909$ \\
\hline 2019 & 626,595 & 750,576 & $1,377,171$ & 2019 & 915,451 & 881,967 & $1,797,418$ \\
\hline 2020 & 624,316 & 852,648 & $1,476,964$ & 2020 & 948,854 & $1,026,292$ & $1,975,146$ \\
\hline Total & $7,324,928$ & $4,343,238$ & $11,668,166$ & Total & $9,002,175$ & $4,887,691$ & $\begin{array}{l}\text { Most costly } \\
13,889,866\end{array}$ \\
\hline
\end{tabular}

Source: Author's calculations based on assumptions in Annex 3. 